\title{
¡CAFE60v1: A 60-Year Large Ensemble Climate Reanalysis. Part II: Evaluation
}

\author{
Terence J. O'Kane, ${ }^{a}$ Paul A. Sandery, ${ }^{\text {a }}$ Vassili Kitsios,,${ }^{\text {bc }}$ Pavel Sakov, ${ }^{\text {d }}$ Matthew A. Chamberlain, ${ }^{\text {a }}$ \\ Dougal T. Souire, ${ }^{\mathrm{a}}$ MARK A. Collier, ${ }^{\mathrm{b}}$ Christopher C. ChAPMAN, ${ }^{\mathrm{a}}$ Russell FiEdler, ${ }^{\mathrm{a}}$ Dylan Harries, ${ }^{\mathrm{a}}$

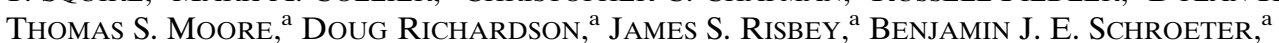

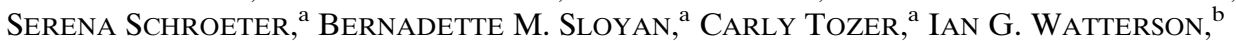 \\ AMANDA Black, ${ }^{a}$ COURTNEY QuinN, ${ }^{a}$ AND RiCHARD J. MATEAR ${ }^{\mathrm{a}}$ \\ ${ }^{\text {a } C S I R O ~ O c e a n s ~ a n d ~ A t m o s p h e r e, ~ H o b a r t, ~ T a s m a n i a, ~ A u s t r a l i a ~}$ \\ ${ }^{\mathrm{b}}$ CSIRO Oceans and Atmosphere, Aspendale, Victoria, Australia \\ ${ }^{\mathrm{c}}$ Laboratory for Turbulence Research in Aerospace and Combustion, Department of Mechanical \\ and Aerospace Engineering Monash University, Clayton, Victoria, Australia \\ ${ }^{\mathrm{d}}$ Bureau of Meteorology, Docklands, Victoria, Australia
}

(Manuscript received 6 July 2020, in final form 8 March 2021)

\begin{abstract}
The CSIRO Climate retrospective Analysis and Forecast Ensemble system, version 1 (CAFE60v1) provides a large (96 member) ensemble retrospective analysis of the global climate system from 1960 to present with sufficiently many realizations and at spatiotemporal resolutions suitable to enable probabilistic climate studies. Using a variant of the ensemble Kalman filter, 96 climate state estimates are generated over the most recent six decades. These state estimates are constrained by monthly mean ocean, atmosphere, and sea ice observations such that their trajectories track the observed state while enabling estimation of the uncertainties in the approximations to the retrospective mean climate over recent decades. For the atmosphere, we evaluate CAFE60v1 in comparison to empirical indices of the major climate teleconnections and blocking with various reanalysis products. Estimates of the large-scale ocean structure, transports, and biogeochemistry are compared to those derived from gridded observational products and climate model projections (CMIP). Sea ice (extent, concentration, and variability) and land surface (precipitation and surface air temperatures) are also compared to a variety of model and observational products. Our results show that CAFE60v1 is a useful, comprehensive, and unique data resource for studying internal climate variability and predictability, including the recent climate response to anthropogenic forcing on multiyear to decadal time scales.
\end{abstract}

KEYWORDS: Data assimilation; Ensembles; Model comparison; Reanalysis data

\section{Introduction}

Retrospective reconstructions, or reanalyses, of the recent global climate are intended to produce state-of-the-art gridded representations of the evolving climate in each of Earth's domains, namely the atmosphere, ocean, land surface, and sea ice. The generation of a reanalysis is a considerable undertaking requiring a global general circulation climate model forced with historical estimates of the radiative gases, including volcanic emissions, anthropogenic $\mathrm{CO}_{2}$, and aerosols. In addition, observations of the atmosphere, oceans, and sea ice must be collected and quality controlled and a data assimilation system developed for the particular application. As already noted (Saha et al. 2010), the majority of atmospheric reanalyses (Kalnay et al. 1996; Compo et al. 2011; Hersbach

\footnotetext{
๑ Denotes content that is immediately available upon publication as open access.
}

Supplemental information related to this paper is available at the Journals Online website: https://doi.org/10.1175/JCLI-D-200518.s1.

Corresponding author: Terence J. O'Kane, terence.okane@ csiro.au et al. 2020; Gelaro et al. 2017; Kobayashi et al. 2015) have been developed from existing numerical weather prediction (NWP) systems where the background state consists of a short forecast from time $t$ to $t+\Delta t$ and where $\Delta t$ defines the window (cycle length) over which observations are gathered and then assimilated, either as an average (synchronously) or alternately by explicitly taking into account the time the observation was taken (asynchronously). In contrast, ocean reanalyses (Smith and Murphy 2007; Penny et al. 2015; Forget et al. 2015; Alves et al. 2004; Carton et al. 2018; Oke et al. 2013; Balmaseda et al. 2013) have employed a wide range of choices for observational windows ranging from a few days (e.g., Oke et al. 2013; Yin et al. 2011), extending out up to several weeks (e.g., Smith and Murphy 2007) and across a disparate range of model resolutions from eddy resolving (e.g., Oke et al. 2013) to zonal resolutions of nearly $2^{\circ}$ (e.g., Alves et al. 2004; Yin et al. 2011).

An ongoing motivation for reanalyses is for the study of climate variability. However, there are still only a very few reanalysis products produced with a fully coupled general circulation model where the available observations of the ocean, atmosphere, and sea ice domains are jointly assimilated. Of these, both the CERA-20C (Laloyaux et al. 2018) (1901-2010) and NCEP-CFSR (Saha et al. 2010) (1979-present) coupled reanalyses are based around NWP systems and feature sophisticated atmospheric data assimilation schemes and assimilation windows of a few hours. To date, only the CERA-20C 
reanalysis provides an ensemble of state estimates (10 members) with which to provide uncertainty estimates. The CSIRO Climate retrospective Analysis and Forecast Ensemble System, version 1 (CAFE60v1) was developed with the express purpose of providing a large ensemble reanalysis over the past 60 years in an attempt to better characterize uncertainties in observations, to estimate model biases, to provide a large ensemble of selfconsistent initial conditions for multiyear climate forecasts, and to incorporate explicit covariances between the respective climate domains to better balance the forecast initial conditions.

O'Kane et al. (2021, hereafter Part I) described the observational data, model configuration, and strongly coupled data assimilation (SCDA) system used to generate the CAFE60v1 reanalysis, including an evaluation of the system performance via the assimilation errors and statistics. Here we undertake a detailed evaluation of the representation of the major climate modes of variability in the tropics (section 2), troposphere (section 3), precipitation and land surface temperatures (section 4), sea ice (section 5), ocean structure and transports (section 6), and ocean biogeochemistry (section 7). A summary and conclusions follow in section 8 .

\section{Tropical variability}

Our examination of tropical variability begins with an analysis of tropical Pacific and Indian Ocean variability. In the results that follow, where principal component (PC) analysis is applied, the PCs are reordered on the basis of the absolute correlation of their respective empirical orthogonal functions (EOFs) to the observed teleconnection pattern. The signs of the EOFs are chosen dependent on the corresponding PC. For the CAFE60v1 ensemble this is applied for each of the 96 individual members.

\section{a. El Niño-Southern Oscillation}

El Niño-Southern Oscillation (ENSO) is the dominant mode of interannual variability in Earth's climate system. In addition, interdecadal changes in the magnitude and frequency of ENSO events and its teleconnections can be seen in both observations and models (see McGregor et al. 2009, and references therein). ENSO variability underwent a noticeable shift in behavior during the late 1970s (Fedorov and Philander 2000) after which La Niña events declined and El Niño events increased in frequency. This climate shift to warmer tropical conditions occurred around 1976-78 and was shown to be forced by subsurface changes in both temperature and salinity in the ocean south of the equator as part of an oscillation intrinsic to the equatorial and southern tropical Pacific (Giese et al. 2002; O'Kane et al. 2014).

In Fig. 1, we first show a comparison of the CAFE60v1 ENSO Niño-3.4 index to that calculated from Hadley Centre Global Sea Ice and Sea Surface Temperature (HadISST; Rayner et al. 2003) and Extended Reconstructed Sea Surface Temperature version 5 (ERSSTv5; Huang et al. 2017). The CAFE60v1 index is calculated from the SST field at the time of analysis for both the individual ensemble members and ensemble mean. We also compare the Southern Oscillation index (SOI) and the leading principal component of the anomalous thermal wind $u_{T}^{\prime}$ [see Eq. (2) of O'Kane et al. (2017)] for JRA55 (Kobayashi et al. 2015) and CAFE60v1. For $u_{T}^{\prime}$ in CAFE60v1, we include both the ensemble mean index and the index computed from the ensemble mean. In Fig. 1 and all subsequent figures, light blue shading indicates the CAFE60v1 ensemble range, the darker blue shading indicates one standard deviation from the mean (i.e., spread), and all anomalies are with respect to the 1980-2018 base period.

The Niño-3.4, SOI, and $u_{T}^{\prime}$ time series are all measures of tropical Pacific variability and its teleconnection to the higher latitudes via the thermal wind, as such all are highly correlated and representative of ENSO variability in SST, surface air temperature (SAT), and the troposphere, respectively. The observed JRA-55 SOI and $u_{T}^{\prime}$ indices are within one standard deviation of the ensemble spread about the corresponding CAFE60v1 ensemble mean value, with the exception of the 1964-65 and 1973-76 La Niña events where the magnitude is overestimated in CAFE60v1. This correspondence is perhaps unsurprising given we assimilate JRA-55 data. However, only monthly mean observations are assimilated thereby adjusting the large scales of the background state of the atmosphere without any attempt to get the details of any particular analysis day correct, after which the model then runs freely for a month and unpredictable internally (model) generated weather systems develop. The atmospheric indices SOI and $u_{T}^{\prime}$ display reduced spread during each particular ENSO event relative to the increased uncertainty observed during quiescent periods when the index is neutral, for example between 1977 and 1982.

For the Niño-3.4 index we include both the CAFE60v1 monthly mean indices and ensemble mean at analysis time (i.e., analyzed daily values) as compared to HadISST and ERSSTv5 data. The first 2 years (1960-62) of CAFE60v1 correspond to a "spinup" period as the surface ocean is constrained to observations after which the observed index is generally within the one standard deviation bound of the ensemble spread about the ensemble mean index. The exception is the period 2000-04, which corresponds to the advent of Argo and the rapid increase in available in situ upper ocean observations. During this 4-yr period we see a systematic offset between the CAFE60v1 ensemble mean and the verification products HadISST and ERSSTv5 as the upper ocean is progressively being constrained with a corresponding systematic reduction in ensemble spread. After 2004 the ensemble spread is on average lower than $0.5^{\circ} \mathrm{C}$ and the mean values within $0.1^{\circ} \mathrm{C}$.

\section{b. Indian Ocean dipole}

In Fig. 1d, we consider the Indian Ocean dipole (IOD) mode index (DMI) (Saji et al. 1999) from HadISST and the CAFE60v1 ensemble. Indian Ocean SST, and in particular, air-sea interactions in the tropical Indian Ocean, is recognized as an important driving factor in the low-frequency variations of the climate. Saji et al. (1999) first proposed the concept of the tropical Indian Ocean dipole, which is characterized by opposite signs of sea surface temperature anomalies (SSTA) in the western and eastern tropical Indian Ocean with positive IOD events associated with anomalously cold (negative) SST close to the coast of Sumatra and anomalously warm (positive) 
a)

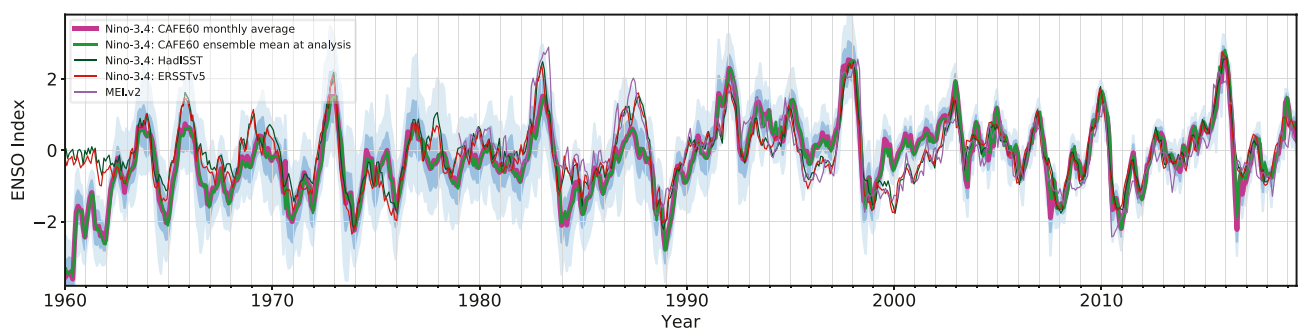

b)

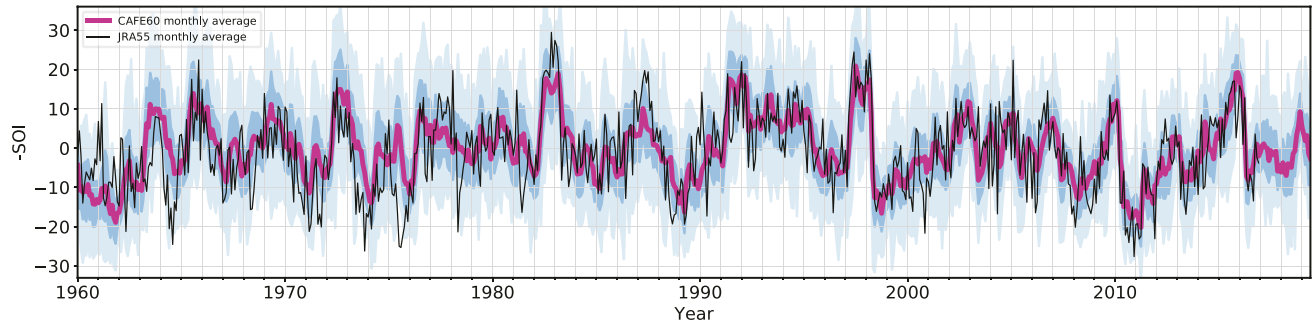

c)

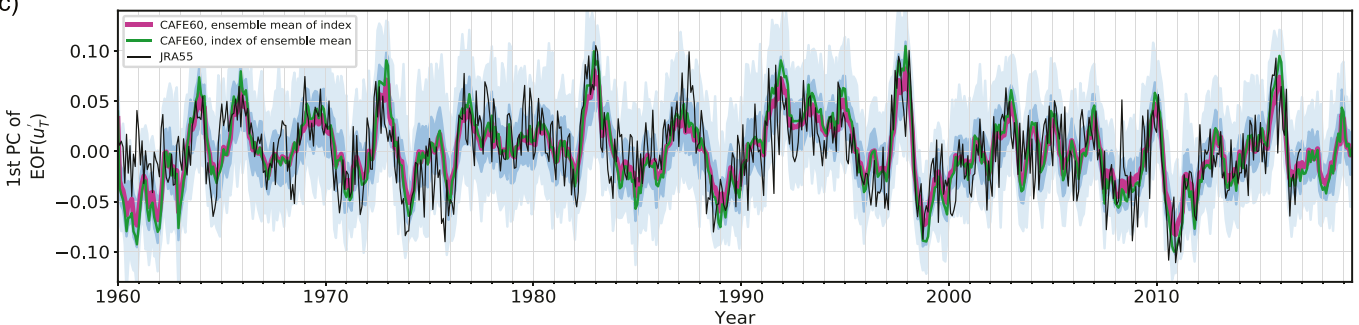

d)

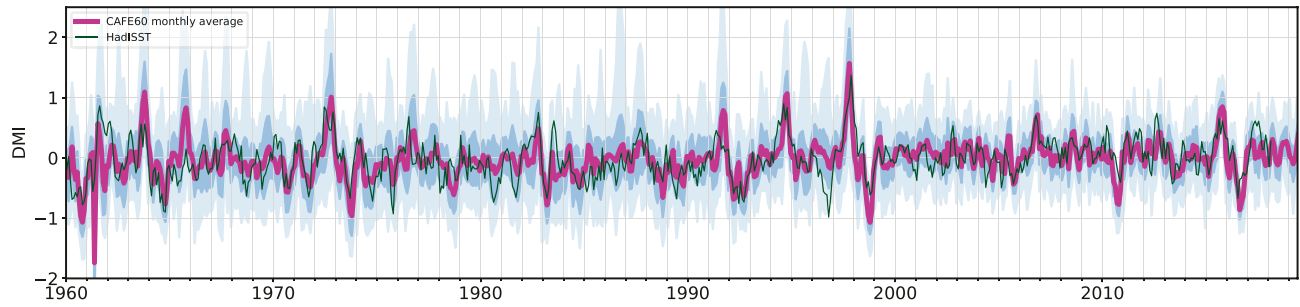

FIG. 1. (a) Comparison of the ENSO Niño 3.4 index $\left({ }^{\circ} \mathrm{C}\right)$ for HadISST, ERSSTv5, and CAFE60v1 calculated from the SST field at the time of analysis (green line) for the individual ensemble members and ensemble mean monthly average (magenta line). (b) The SOI index calculated from JRA-55 and the CAFE60v1 ensemble. (c) The leading principal component of the anomalous thermal wind $u_{T}^{\prime}$ for JRA-55, the CAFE60v1 ensemble mean index, and index of the ensemble mean. (d) The Indian Ocean dipole mode index (DMI; ${ }^{\circ} \mathrm{C}$ ) from HadISST and the CAFE60v1 ensemble and ensemble mean. Note that the light blue shading indicates the CAFE60v1 ensemble range; the darker blue shading indicates one standard deviation from the mean. All anomalies are w.r.t. a 1980-2018 base period.

SST in the western part of the basin. Strong external forcing by particular ENSO events can trigger IOD events (Meyers et al. 2007). The IOD is strongly connected with precipitation anomalies in eastern Africa and Indonesia. Comparison of the IOD calculated from HadISST and the CAFE60v1 ensemble mean (Fig. 1d) show the observed indices within one standard deviation of the CAFE60v1 ensemble mean over the entire record with the largest IOD events coincident with the ENSO events of 1973, 1983, 1998, and 2010-11. There is also a noticeable reduction of up to $1^{\circ} \mathrm{C}$ in spread in the CAFE60v1 ensemble spread post 2000 although not to the same degree as evident in the Niño-3.4 index. The question arises as to whether this is due to more complete ocean observations or if there is a true change in the dynamics.

\section{c. Madden-Julian oscillation}

The Madden-Julian oscillation (MJO) (Madden and Julian 1971 ) is the dominant intraseasonal mode of tropical variability and is characterized as an eastward-propagating mode with a 30-90-day period, involving Rossby and Kelvin wave interactions (Kitsios et al. 2019) and initiated by deep convection within the Maritime Continent (Zhang 2005). During the MJO cycle in the convective region, the zonal winds converge in the lower troposphere $(\sim 850 \mathrm{hPa})$ and diverge in the 
a)
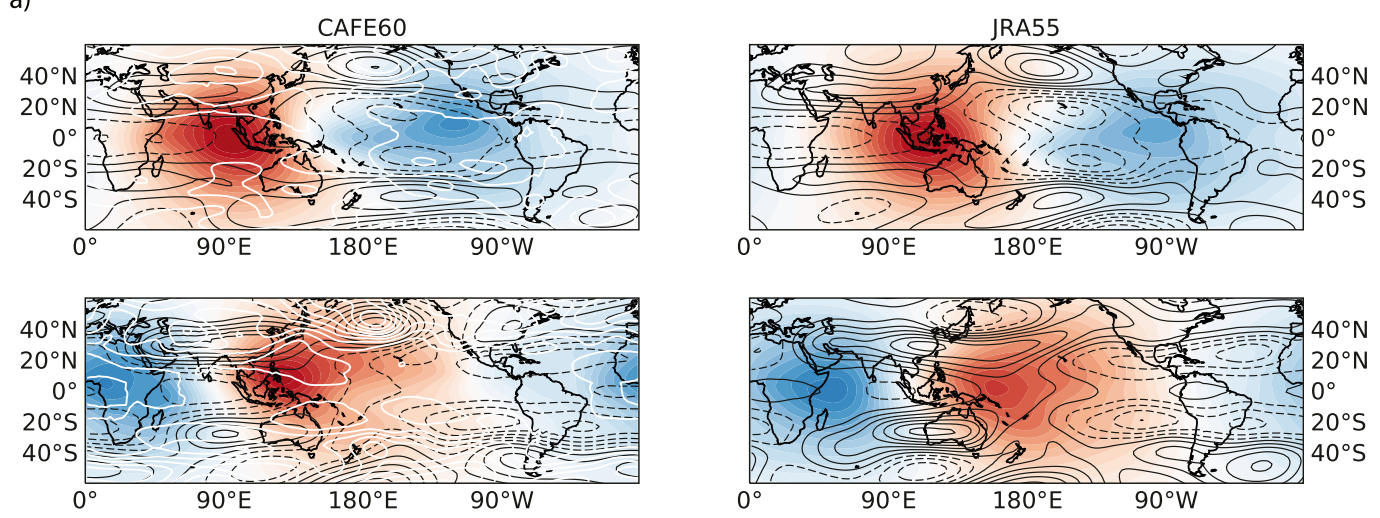

$-0.015$

0.000

0.015

b)

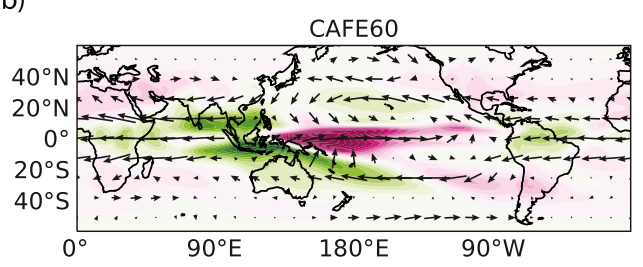

$\left.\Delta \chi^{\prime}\right|_{850-150}$

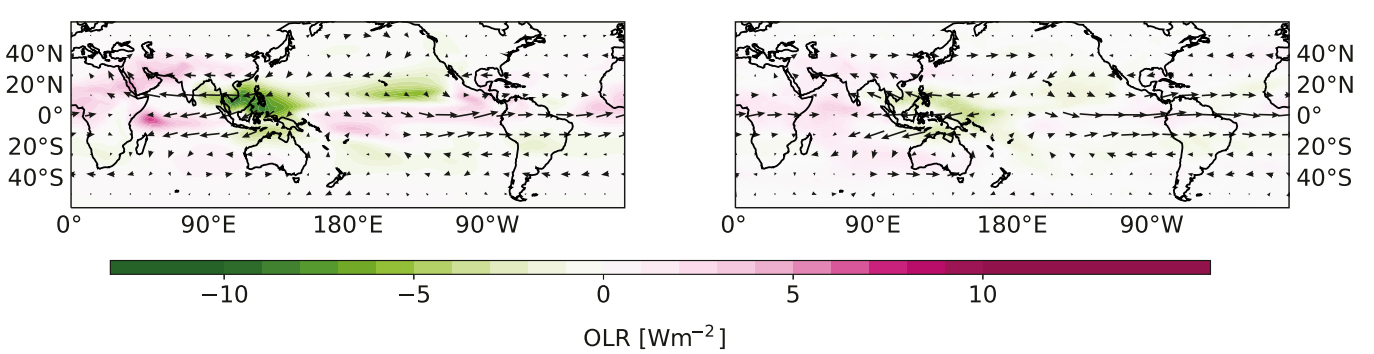

FIG. 2. (a) The two leading patterns based on principal components of the daily 850-hPa minus 150 -hPa global velocity potential and their regression onto 150 -hPa geopotential height (black) contours. The EOFs are nondimensional. White lines are the ensemble spread (1 std) of regression pattern of the corresponding PCs onto geopotential height at $150 \mathrm{hPa}$. (b) The regression onto OLR and the ensemble mean wind direction pattern resulting from the regression of PCs onto $u$ and $v$ wind anomalies at $150 \mathrm{hPa}$.

upper troposphere $(\sim 150 \mathrm{hPa})$ where the large-scale convective system propagates eastward before decaying in the western Pacific.

Following Adames and Wallace (2014), in Fig. 2a we show the two leading patterns (EOFs) of a principal component analysis (PCA) of the daily $850-\mathrm{hPa}$ minus $150-\mathrm{hPa}$ global velocity potential $\left.\nabla \chi^{\prime}\right|_{(850-150)}$ and their regression onto 150$\mathrm{hPa}$ geopotential height (black) contours. The EOFs are nondimensional (i.e., L2 norm is equal to 1 ). The white lines in the left panels indicate the CAFE60v1 ensemble spread (one standard deviation) of the regression pattern of the corresponding PCs onto geopotential height at $150 \mathrm{hPa}$. The ensemble mean regression onto outgoing longwave radiation (OLR) and the ensemble mean wind direction pattern resulting from the regression of the PCs onto zonal and meridional wind anomalies at $150 \mathrm{hPa}$ are shown in Fig. 2b. Whereas the amplitude of the OLR regression patterns and wind direction vectors is larger when using CAFE60v1 ensemble mean fields relative to those from the JRA-55 reanalysis, the general patterns are similar. Time series of amplitude and phase of the MJO in terms of daily $\left.\nabla \chi^{\prime}\right|_{(850-150)} \mathrm{m}^{2} \mathrm{~s}^{-1}$ global velocity potential are shown in Fig. 1 in the online supplemental material. For both amplitude and phase we observe that the JRA55 MJO index lies within one standard deviation of both the CAFE60v1 ensemble mean MJO index and the MJO index of the ensemble mean. As with the IOD, particular ENSO events are evident notably those in 1973, 1983, 1998, and 2010-11.

\section{Midlatitude troposphere}

One of the most challenging tasks for the CAFE60v1 reanalysis is the representation of the midlatitude troposphere. The basic premise we have employed in generating CAFE60v1 is that monthly mean atmospheric increments consistent with 
a)
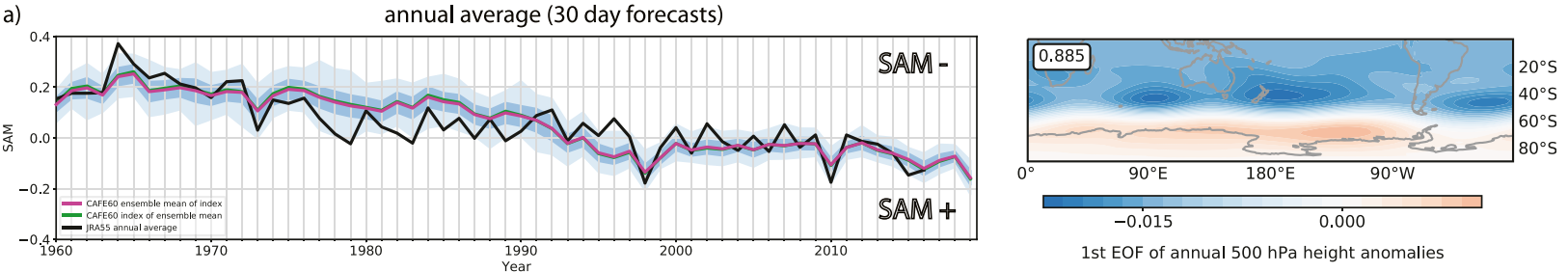

b)
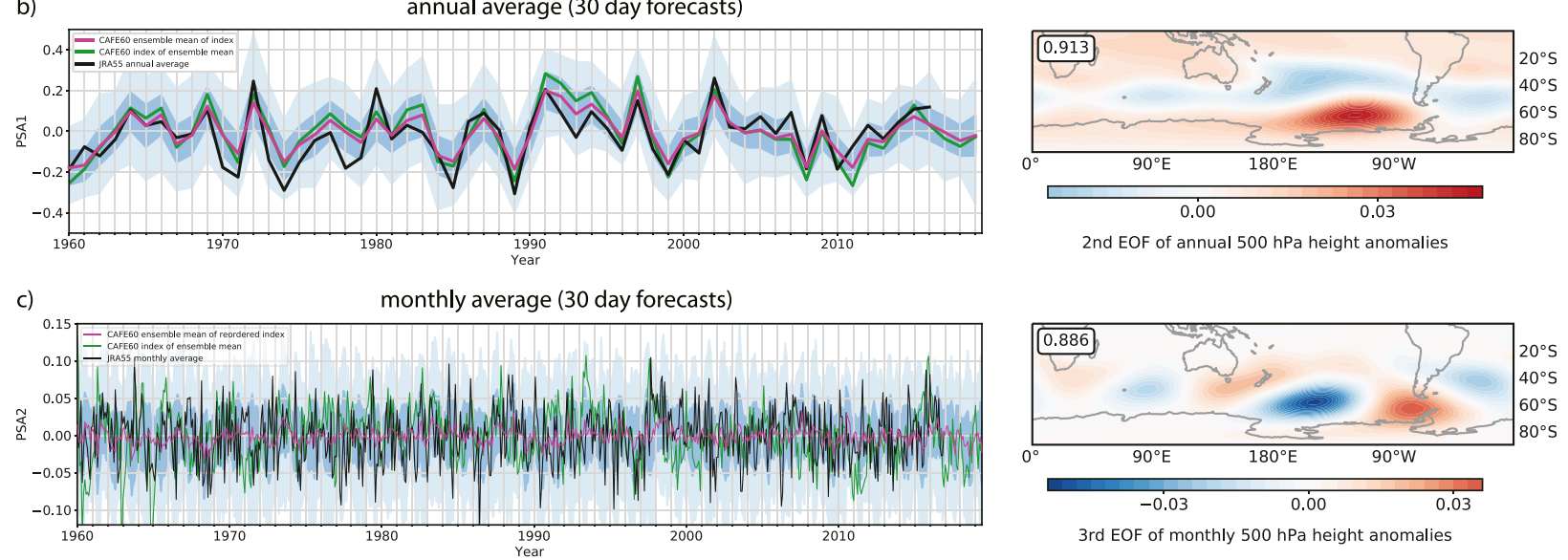

FIG. 3. (a) Annual means of the CAFE60v1 SAM index calculated as the leading PC of daily 500-hPa geopotential height data and the corresponding nondimensional EOF1 spatial pattern and its correlation with JRA-55. Similar calculations are shown for (b) the annual mean PSA1 mode and (c) for the monthly mean PSA2 mode. The shading again indicates one standard deviation (dark blue) and ensemble spread (light blue).

surface temperature gradients and the ocean state can be used to constrain the large scales of the atmosphere, for example the jets and cells. As a consequence, we expect that the statistics of the synoptic features (i.e., the frequency of occurrence and persistence of coherent patterns, rather than the specific features observed on any given day) will be generated by the model dynamics consistent with the adjusted large-scale structures. Systematic differences between CAFE60v1 and other atmospheric reanalyses arise principally through the use of a monthly cycle length and monthly atmospheric observations, in contrast to the standard 6-hourly cycle length and observations typical of atmospheric reanalyses based on NWP systems. The long cycle length in CAFE60v1 allows unpredictable internally generated variability to grow in contrast to a short 6-hourly cycle and is the cause of the differences, rather than model errors per se.

\section{a. Southern Hemisphere}

We first consider midlatitude tropospheric variability in the Southern Hemisphere via an EOF analysis of 500-hPa geopotential height $\left(Z_{500 \mathrm{hPa}}\right)$. The leading mode EOF1 pattern of $Z_{500 \mathrm{hPa}}$ anomalies relative to 1980-2018, shows a strong zonal symmetry at high latitudes, and a zonal wavenumber-3 structure with centers located in the Indian, Pacific, and Atlantic sectors of the Southern Ocean. This structure defines the southern annular mode (SAM) (Mo 2000), also known as the Antarctic Oscillation. SAM is the dominant mode of variability in the mid- to high latitudes and characterizes north-south variations of the westerly wind belt around Antarctica. In its negative phase, the SAM expands the zonal band of strong westerly winds (polar jet) toward the equator. In contrast a positive SAM phase sees the strong midlatitude jet contract poleward, weakening the ability for cold fronts to impact southern Australia, South Africa, and South America (Gillett et al. 2006). Variations in the latitudinal position of the westerlies influence midlatitude storm systems, and, in combination with the winter subtropical jet, are an important driver of rainfall variability in southern Australia.

Over recent decades a noticeable trend toward the positive SAM phase has been documented in both observations, reanalyses, and climate projections (Swart et al. 2015). In Fig. 3a we see a trend toward a stronger zonal jet and poleward movement of the westerlies (i.e., the positive SAM phase) in the leading EOF/PC. Note that the negative sign of the PC time series is multiplied by the EOF pattern to give a positive trend. That is, an increasingly positive SAM is defined by a negative trend in the leading PC of $Z_{500 \mathrm{hPa}}$. As the SAM index is highly multiscale without clear scale separation, we have shown only the annual average as on monthly or shorter time scales the correlation between CAFE60v1 and the observed SAM index is quite low, again an indication that fast synoptic-scale features are not well captured for the SAM in CAFE60v1.

The EOF 2 and 3 patterns of $Z_{500 \mathrm{hPa}}$ are known as the PacificSouth American (PSA) modes (Lau et al. 1994; O'Kane et al. 
2017) and are characterized as well-defined wave trains (wave 3 or 4) extending from southeastern Australia to Argentina, whose centers are located at $60^{\circ} \mathrm{S}, 120^{\circ} \mathrm{W}$ (PSA1) and $60^{\circ} \mathrm{S}$, $90^{\circ} \mathrm{W}$ (PSA2), respectively. The PSA1, on interannual time scales, is typically associated with low-frequency ENSO variability and a dominant period of 40-48 months. The PSA2 mode is associated with the quasi-biennial component of ENSO variability and a period of 26 months. Figure $3 \mathrm{~b}$ shows annual averages of PSA1 (EOF/PC 2) and monthly averages of PSA2 (EOF/PC 3) of $Z_{500 \mathrm{hPa}}$. The JRA-55 PSA1 (annual average of 30-day forecasts) and PSA2 (monthly averaged forecasts) indices are largely within one standard deviation of the CAFE60v1 ensemble mean PSA1 index and the PSA1 index of the ensemble mean. The right-hand panels show the corresponding CAFE60v1 EOFs of the ensemble mean and their pattern correlation to JRA-55, which exceed 0.88 for all modes, an indication that, like SAM, the low-frequency (annual averaged) statistics and trends of the midlatitude synoptic features are well captured. That the monthly CAFE60v1 PSA2 index of the ensemble mean also matches the monthly JRA-55 PSA2 index an indication that both the frequency and location of occurrence of the large-scale synoptic features are well represented in CAFE60v1 despite no attempt to constrain the system to the coherent features of the midlatitude synoptic observations. This result indicates the importance of vacillations in the strength and spatial characteristics of the polar and subtropical jets on the formation and variations of synopticscale midlatitude systems.

\section{b. Northern Hemisphere}

In contrast to the zonally oriented wave train teleconnection modes of the Southern Hemisphere, the Northern Hemisphere midlatitude teleconnections are larger scale, more persistent, and characterized by meridionally oriented dipolar structures occurring in the Pacific [i.e., the Pacific-North American (PNA) pattern] and in the Atlantic [i.e., the North Atlantic Oscillation (NAO)]. Both the PNA and NAO indices are calculated using a station-based index. For the NAO this is calculated as the difference of normalized sea level pressure (SLP) between Lisbon, Portugal, and Stykkisholmur/Reykjavik, Iceland (Hurrell 1995). For the PNA we use the index of Wallace and Gutzler (1981) derived from PNA $=0.25 \times$ $\left[Z_{500 \mathrm{hPa}}\left(20^{\circ} \mathrm{N}, 160^{\circ} \mathrm{W}\right)-Z_{500 \mathrm{hPa}}\left(45^{\circ} \mathrm{N}, 165^{\circ} \mathrm{W}\right)+Z_{500 \mathrm{hPa}}\left(55^{\circ} \mathrm{N}\right.\right.$, $\left.\left.115^{\circ} \mathrm{W}\right)-Z_{500 \mathrm{hPa}}\left(30^{\circ} \mathrm{N}, 85^{\circ} \mathrm{W}\right)\right]$. The NCEP NAO/PNA indices use daily data based on the rotated principal component analysis (RPCA) first developed by Barnston and Livezey (1987) (https:// www.cpc.ncep.noaa.gov/).

As the dominant mode of variability in the North Pacific, the PNA exhibits at times a pressure "seesaw" in the Aleutian low (Wallace and Gutzler 1981) and a wavelike structure across the North Pacific (Barnston and Livezey 1987) with marked seasonal variations in the wavelength of the Rossby wave train. In Fig. 4a we compare the monthly mean PNA index calculated from JRA-55 and the CAFE60v1 ensemble. The CAFE60v1 ensemble mean PNA index captures the larger more persistent PNA events but is less able to track observed rapid variations in the index at particular times. However, the increased variability evident in JRA-55 is mostly contained within the
CAFE60v1 ensemble spread. A comparison of CAFE60v1 and the NOAA NCEP index is included in supplemental Fig. 2 where we observe that the NOAA NCEP index displays larger variance relative to both JRA-55 and CAFE60v1. For a station-based index, differences between model resolution for the reanalyses manifest in the ability to resolve high-frequency temporal variability, which is better resolved in well-sampled purely observational estimates.

The NAO is the dominant tropospheric teleconnection in the Atlantic. A positive NAO phase is characterized by a stronger than average subpolar low and subtropical high resulting in a strengthened Atlantic jet stream and a northward shift of the storm track. The negative phase occurs when both the subpolar low and the subtropical high are weaker than average and as a consequence the Atlantic jet stream and storm track have a more west-to-east orientation. Significant biases in our model over the Euro-Atlantic sector (not shown), also evident in CMIP5 models of similar resolution (Davini and Cagnazzo 2014; Davini and D'Andrea 2016), that re-emerge within the month between assimilation cycles for the NAO make this the most poorly represented midlatitude mode of variability in the troposphere for CAFE60v1 as evident in annual averages of the CAFE60v1 ensemble mean (supplemental Fig. 2b).

The Arctic Oscillation or northern annular mode (NAM) appears as a ring of sea level pressure anomalies about the high northern latitudes and modulates the ability for Arctic air to penetrate into midlatitudes. Analogous to SAM, we can define the NAM as the leading EOF/PC of $\mathrm{NH} Z_{1000 h P a}$ data. In Fig. $4 \mathrm{~b}$ we examine the NAM using lead-zero daily $Z_{1000 \mathrm{hPa}}$ (i.e., the analyzed lower troposphere) in order to ascertain the effectiveness of the assimilation. Here we see the JRA-55 NAM index within one standard deviation of the ensemble CAFE60v1 index values. This indicates that the data assimilation is able to constrain the model quite substantially despite employing monthly mean increments. Although pattern correlations exceed 0.8 (Fig. 4c), differences between the CAFE60v1 ensemble mean of the EOF pattern and that from JRA-55 shows significant model bias over the Atlantic and Pacific that is greatly reduced in comparison to the EOF of the ensemble mean. This indicates the filtering effect of taking the ensemble average prior to performing the EOF/PCA. These biases can rapidly amplify over the month between assimilation leading to increased noise and a reduced correspondence to indices calculated from monthly mean data as we saw in Fig. 4a for the PNA. The results for the NAM highlight the utility of the analysis ensemble for understanding climate variability over the recent decades and possible use of the background (forecasts) for assessing systematic model errors.

\section{c. Blocking}

To better understand synoptic-scale variability in CAFE60v1 we consider the distribution and frequency of atmospheric blocking. Here we apply the Tibaldi-Molteni index (Tibaldi and Molteni 1990). Previous studies of blocking in the Northern Hemisphere have revealed significant improvements in reproducing blocking climatologies in the Pacific but less so for the Euro-Atlantic sector (Davini and D'Andrea 2016). In 
a) monthly average (30 day forecasts)

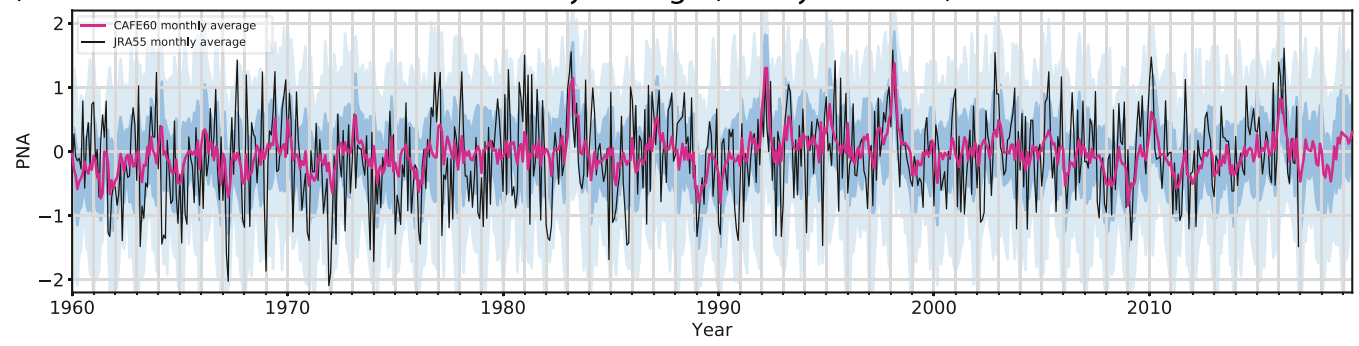

b)

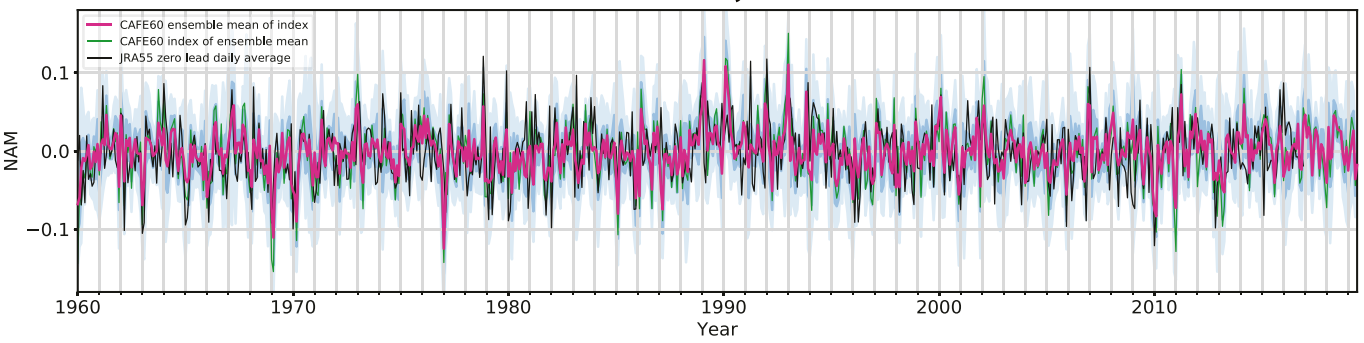

c)

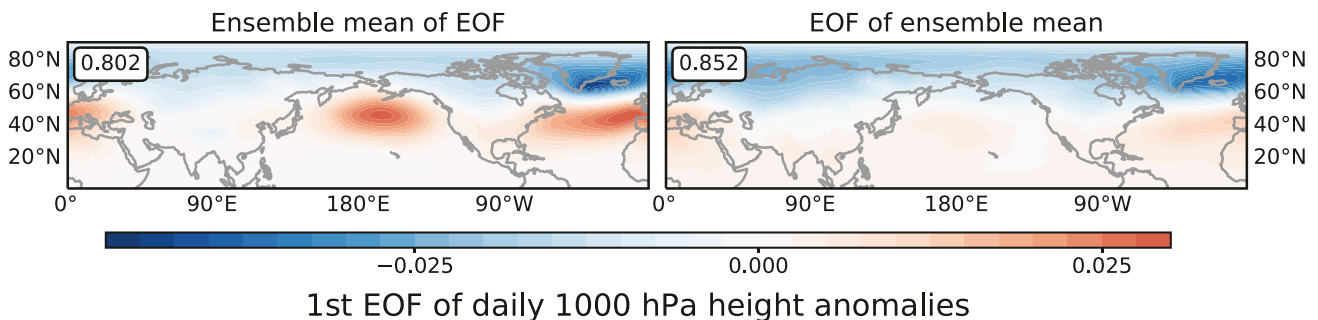

FIG. 4. As in Fig. 1, but for (a) the monthly mean PNA station index and (b) the northern annular mode/Arctic Oscillation EOF-based index for lead-zero daily PCs. (c) Differences between JRA-55 $Z_{1000 \mathrm{hPa}}$ EOF1 and the CAFE60v1 ensemble mean of the $Z_{1000 \mathrm{hPa}}$ EOF1 and similarly the CAFE60v1 $Z_{1000 \mathrm{hPa}}$ EOF1 pattern of the ensemble mean. Correlations of the CAFE60v1 and JRA-55 patterns are shown in the insets. Model biases in the Pacific Ocean evident in the ensemble mean of member EOFs are not evident when considering the EOF of the ensemble mean. All EOFs are nondimensional.

Fig. 5 comparison is made of the daily Tibaldi-Molteni blocking index averaged between 1990 and 1994 for JRA-55, NCEPNCAR reanalysis 1 (Kalnay et al. 1996), the CAFE60v1 ensemble mean (96 members), and 18 individual members of the CAFE60v1 ensemble. We further include the index for two distinct $60-\mathrm{yr}$ periods of the model control simulation. The index is calculated with daily CAFE60v1 geopotential height. On monthly time scales, coherent synoptic features are largely uncorrelated across the respective ensemble members due to phase differences hence, we focus on the ensemble mean Tibaldi-Molteni index rather than the TibaldiMolteni index of the ensemble mean. For the Northern Hemisphere, quite large diversity is seen in the index of particular ensemble members; however, there is close agreement between the CAFE60v1 ensemble mean and control indices. Both the model and reanalysis generally reproduce the observed climatology of blocking well in all sectors apart from the Euro-Atlantic sector between $340^{\circ} \mathrm{E}$ and $0^{\circ}$ for reasons discussed previously. For the Southern Hemisphere, we observe quite different blocking climatologies in the Pacific (25\% at the peak) for the control simulations. The CAFE60v1 ensemble mean index improves on the control simulations between $250^{\circ}$ and $300^{\circ} \mathrm{E}$ over North America. The peak blocking in the mid-Pacific Ocean $\left(\sim 210^{\circ} \mathrm{E}\right)$ indicates higher frequency of occurrence in JRA-55 relative to NCEP N1 and CAFE60v1 ensemble mean, presumably related to the higher horizontal resolution in the former.

\section{Surface air temperature and precipitation}

Two of the key indicators of near-term global climate variability are surface air temperature (SAT) and precipitation. Both are key variables in forecasts contributed to the WMO Lead Centre for Annual-to-Decadal Climate Prediction (http://www.wmolc-adcp.org). Comparison of the CAFE60v1 ensemble mean surface air temperature to independent estimates 


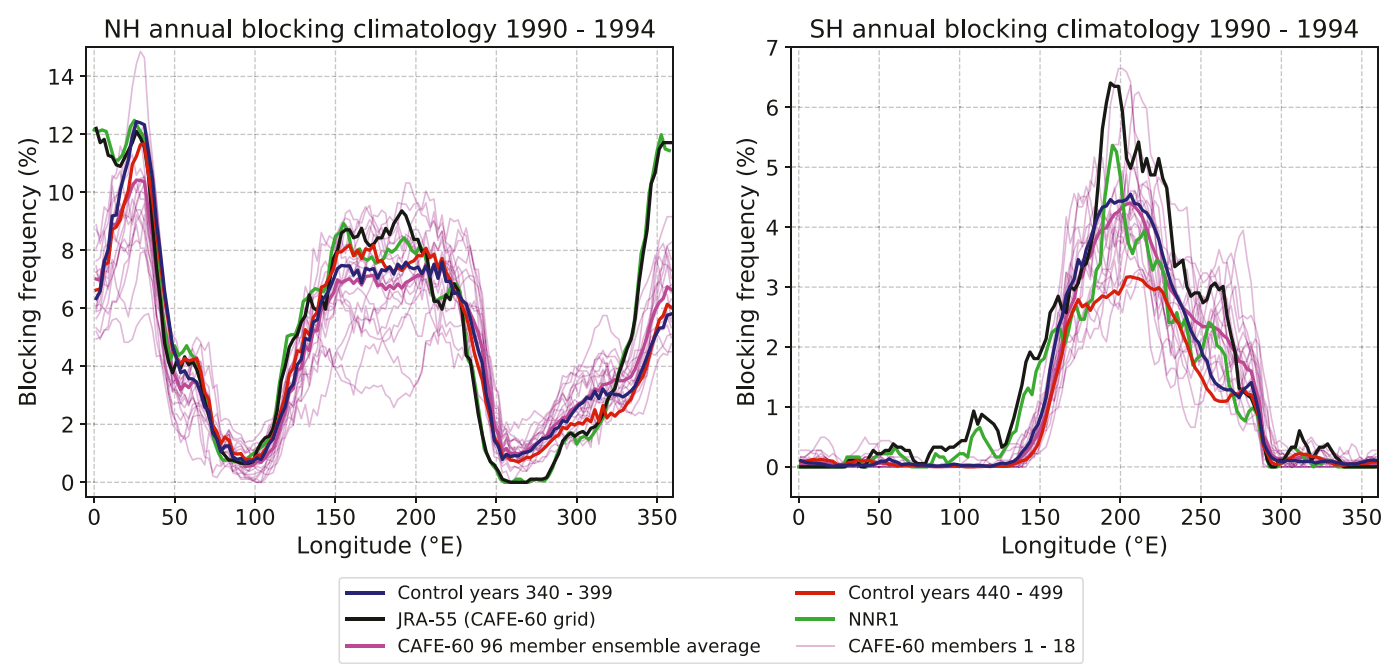

FIG. 5. Comparison of the daily Tibaldi-Molteni blocking index averaged between 1990 and 1994 for JRA-55, NCEP NR1, the CAFE60v1 ensemble mean index, and 18 individual members sampled from the CAFE60v1 ensemble. We further include the index for two distinct 60 -yr periods of the model control simulation.

from Australian Gridded Climate Data v1.0.0 AWAP (BoM 2019), the Hadley Centre of the U.K. Met Office land surface air temperature record (HadCRUT4), (Morice et al. 2012) and the ECMWF ERA5 reanalysis (Hersbach et al. 2020) atmospheric reanalysis are shown in Fig. 6. The comparison is made over the globe, over designated regions of the ocean and over Australia. For the globe (Fig. 6a) prior to 1990, 12-month running averages of SAT show CAFE60v1 somewhat cooler (up to $0.5^{\circ} \mathrm{C}$ ) than both ERA5 and HadCRUT4; however, post 1990 there is improved agreement. Similarly for anomalous global SAT, correspondence between CAFE60v1, ERA5, and HadCRUT4 anomalies improves post 2003 coincident with the dramatic increase in subsurface ocean observations. That said, differences in anomalous SAT pre 2003 are between $0.2^{\circ}$ and $0.3^{\circ} \mathrm{C}$ at their maximum. The largest differences of up to $0.3^{\circ} \mathrm{C}$ between ERA5 and the ensemble mean CAFE60v1 SAT occur in the tropics (OEQ) between 1992 and 2008 (Fig. 6b). Over the Southern Hemisphere midto high latitudes (OSH) and subtropical (OSM, ONM) oceans and ERA5 differences are generally less than $0.1^{\circ} \mathrm{C}$, with the 6-month running mean OEQ SAT also showing similar difference values post 2003. Over the Australian continent post 1995 (not shown), there are some clear differences in the 12-month running averaged mean SAT across the three products with generally improved agreement for the anomalous 3-month running mean SAT apart from some obvious differences between 1990 and 2000.

For precipitation, we compare CAFE60v1 to ERA5 and data from the Global Precipitation Climatology Project (GPCP) (Adler et al. 2018) (Fig. 7). The global mean value from GPCP of approximately $2.6 \mathrm{~mm} \mathrm{day}^{-1}$ is considerably less than the average value of $2.9 \mathrm{~mm} \mathrm{day}^{-1}$ for ERA5 and CAFE60v1. The wet bias relative to GPCP in both CAFE60v1 and ERA5 is consistent with similar biases reported in tropical precipitation by Scaife et al. (2018). Both
GPCP and ERA5 12-month running mean anomalies display a relatively larger (between $\pm 0.05 \mathrm{~mm} \mathrm{day}^{-1}$ ) interannual variability in contrast to CAFE60v1 (Fig. 7a). Over the oceans (Fig. 7b) the variability of 12-month global mean precipitation in CAFE60v1 and ERA5 are less than $0.1 \mathrm{~mm} \mathrm{day}{ }^{-1}$ in all regions apart from considerably higher values of up to $1 \mathrm{~mm} \mathrm{day}{ }^{-1}$ for CAFE60v1 over the equatorial ocean (OEQ) during the 1980s and 1990s and lesser values of up to $0.3 \mathrm{~mm}$ day $^{-1}$ between 1980 and 2000 for the ONM region. The 3-month running mean anomalous precipitation in the OEQ region displays very similar variability apart from a period in the early 1990s where CAFE60v1 displays quite large positive anomalies whereas the anomalous ERA5 is largely negative. Over Australia (Fig. 7b) we can also make additional reference to available AWAP data (BoM 2019). Here differences of less than $0.2 \mathrm{~mm} \mathrm{day}^{-1}$ between AWAP and ERA5 occur in both 12 month and 3-month running averages. From 2000 onward, differences between CAFE60v1, AWAP and ERA5 for both the 12-month and 3-month running averaged mean and anomalous precipitation become progressively reduced attaining comparable values between all three products over the most recent two decades.

\section{Sea ice}

Sea ice extent (SIE) mean, climatology, variability, and trends in observations [GIOMAS (Global Ice-Ocean Modeling and Assimilation System; Zhang and Rothrock 2003), NSIDC (National Snow and Sea Ice Data Center; https://nsidc.org/), and HadISST (Rayner et al. 2003)] and models (CAFE control simulation and CMIP6 ensemble) are compared to the CAFE60v1 ensemble (Figs. 8 and 9). For Antarctic SIE, we noted a close correspondence between CAFE60v1, CAFE control, HadISST, GIOMAS, and NSIDC in the mean and 


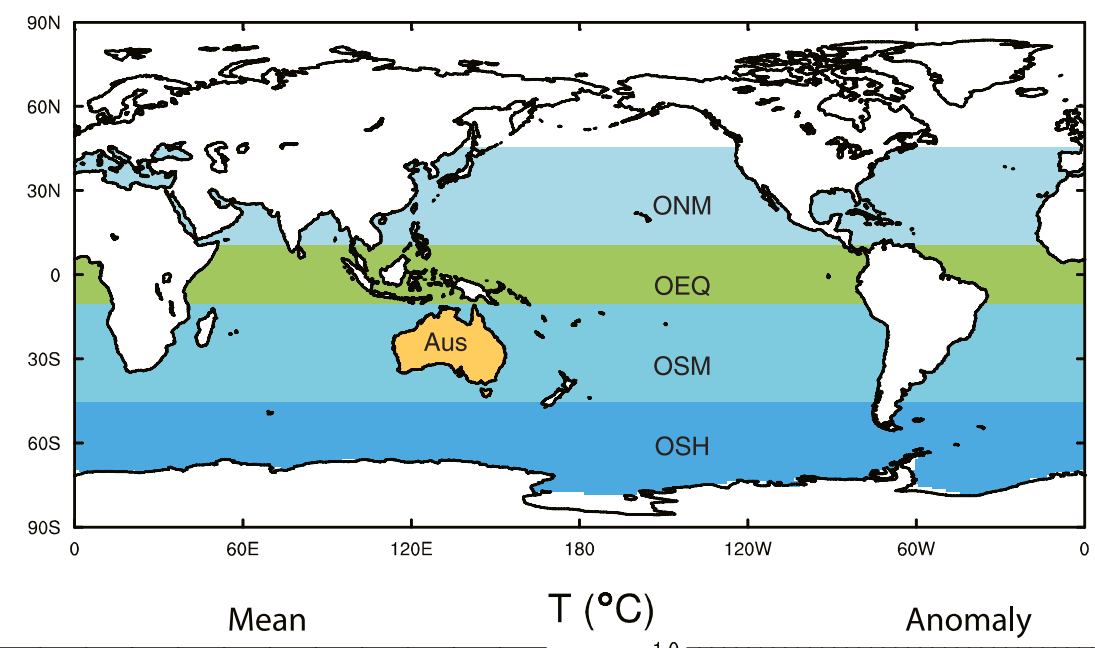

a)

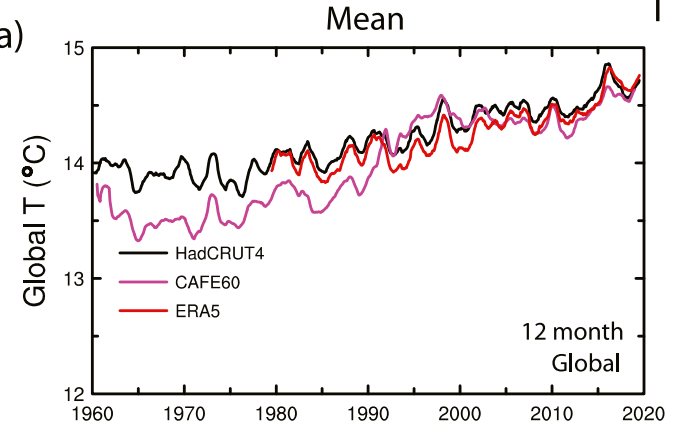

b)

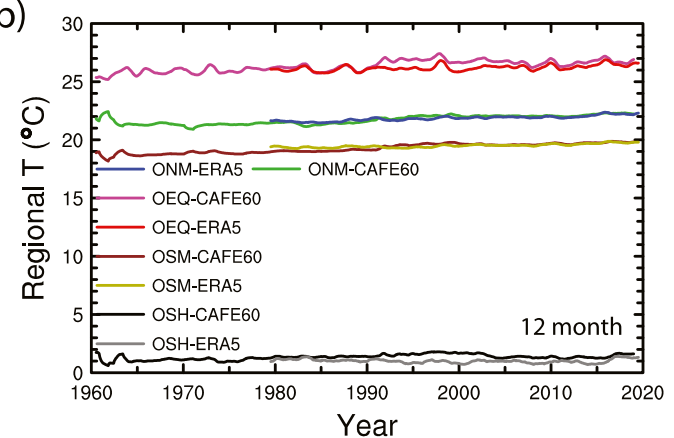

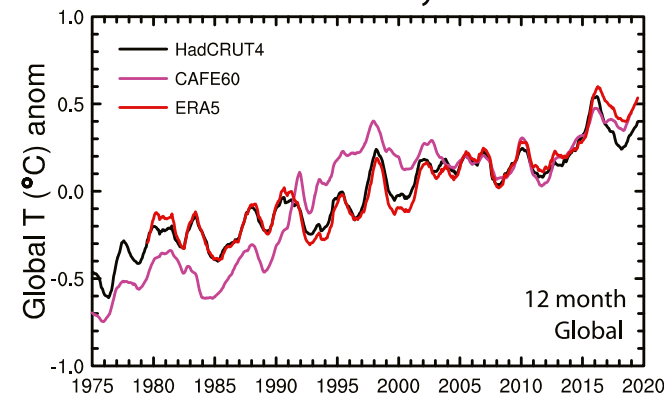

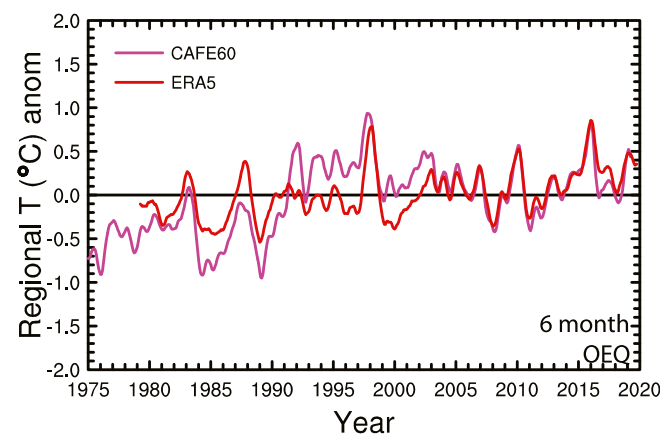

FIG. 6. (a) Comparison of (left) global annual mean and (right) anomalous surface air temperature in the ensemble mean CAFE60v1, HadCRUT4, and ERA5 data. (b) Ensemble mean CAFE60v1 and ERA5 annual (12 month) running mean ocean surface air temperature for the zonal domains indicated (top panel) and biannual (6-month running mean) averages over the equatorial oceans.

variability with the CMIP6 models displaying a very large range of behaviors (Shu et al. 2020). This comparison was also found to be qualitatively the same for the seasonal cycle of SIE however, CAFE60v1 tends to overestimate winter and underestimate summer Antarctic SIE. For Antarctic SIE trends, the CMIP6 models all trend negatively at nearly all longitudes whereas the CAFE60v1 ensemble ranges between $\pm 200 \mathrm{~km}^{2} \mathrm{yr}^{-1}$ in line with the observed trends but with the opposite sign in the western sector.

In the Arctic, CAFE60v1 was found to closely match the observed trends, in particular trends in HadISST, and variability. The CMIP6 models all perform similarly with a significant reduction in the range of behaviors previously evident for Antarctic SIE. The CAFE control mean and climatology showed significantly too much winter SIE with only two CMIP6 models having greater extent, but close to the observed HadISST summer values. CAFE60v1 SIE showed the climatological values uniformly shifted by $\sim 5 \times 10^{6} \mathrm{~km}^{2}$ such that the winter SIE values are very close to the NSIDC and GIOMAS values but the summer SIE had collapsed to very low values.

The CAFE60v1 ensemble spread for September and February sea ice concentration (SIC; see supplemental Fig. 3) generally reflects the SIE results with largest values in regions where sea ice variability is large, with the correct extent in Antarctica during September and the Arctic in February but 


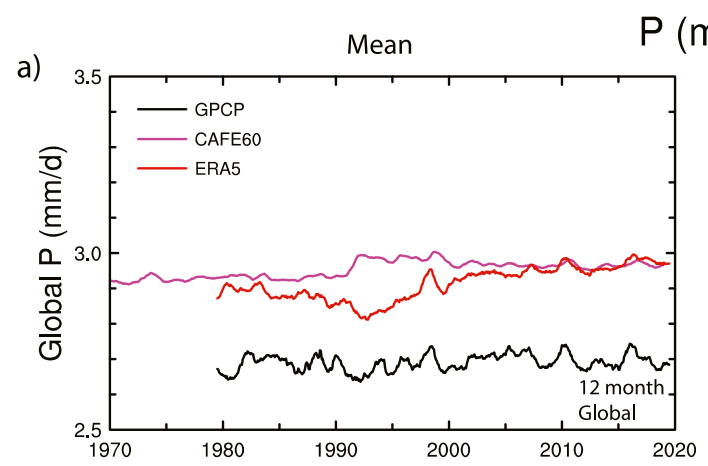

$P(\mathrm{~mm} / \mathrm{d})$

Anomalies
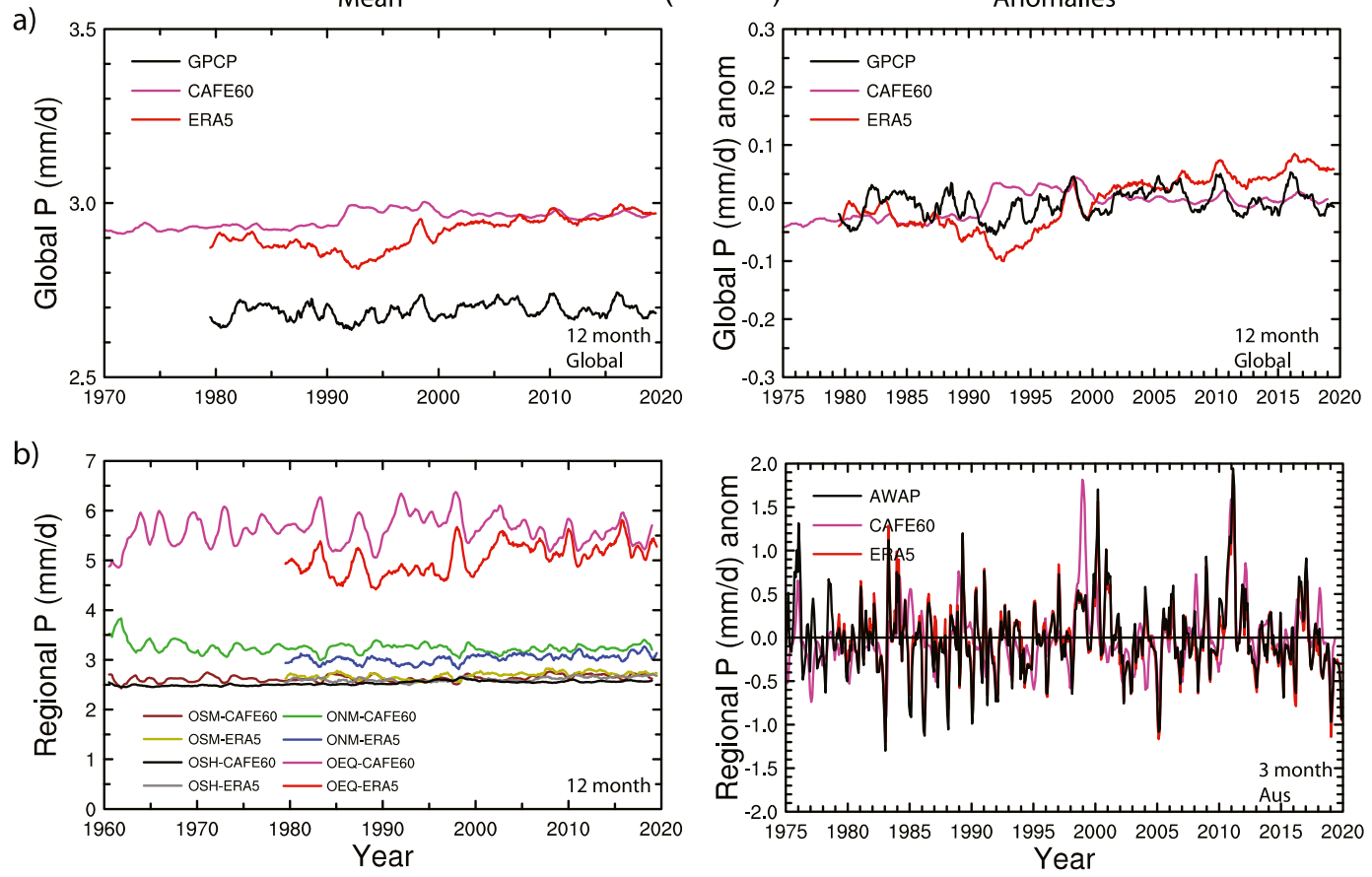

FIG. 7. (a) Comparison of (left) global annual mean and (right) anomalous precipitation in the ensemble mean CAFE60v1, GPCP, and ERA5 data. (b) (left) Ensemble mean CAFE60v1 and ERA5 annual mean precipitation over the ocean for the zonal domains indicated in Fig. 6 and (right) seasonal precipitation over Australia in AWAP, ERA5, and the ensemble mean CAFE60v1 data.

with far too little Arctic sea ice in September. The low Arctic summer sea ice is in part related to insufficient multiyear ice in CAFE60v1.

\section{Ocean}

\section{a. Interdecadal Pacific oscillation and the Atlantic multidecadal oscillation}

The Pacific-wide interdecadal Pacific oscillation (IPO) (Power et al. 1999) characterizes the decadal variability of SST over the entire Pacific basin, comprising variations due to ENSO, the North Pacific decadal oscillation (PDO) (Mantua et al. 1997), and the South Pacific decadal oscillation (Chen and Wallace 2015; Lou et al. 2019). Changes in the phase of the IPO over recent decades have been associated with variations in global mean surface temperature and attributed to the rate of external forcing [i.e., anthropogenic global warming (Kosaka and Xie 2013) and or natural and internal processes (Risbey et al. 2014)]. Here we define the IPO using the tripole index (TPI) of Henley et al. (2015) defined as the difference between SST anomalies (SSTA) averaged over the central equatorial Pacific $\left(\mathrm{T} 2 ; 10^{\circ} \mathrm{S}-10^{\circ} \mathrm{N}, 170^{\circ} \mathrm{E}-90^{\circ} \mathrm{W}\right)$ and the average of the SSTA in the northwest $\left(\mathrm{T} 1 ; 25^{\circ}-45^{\circ} \mathrm{N}, 140^{\circ} \mathrm{E}-145^{\circ} \mathrm{W}\right)$ and southwest Pacific $\left(\mathrm{T} 3 ; 50^{\circ}-15^{\circ} \mathrm{S}, 150^{\circ} \mathrm{E}-160^{\circ} \mathrm{W}\right)$ where $\mathrm{TPI}=$ $\mathrm{T} 2-0.5(\mathrm{~T} 1+\mathrm{T} 3)$.

In Fig. 10 (upper-left panel) we compare the TPI calculated from ACCESS-CM2 CMIP6 historical and control simulations (two realizations) (Bi et al. 2020), ERA5, HadISST, and the CAFE60v1 ensemble and ensemble mean SSTA. Here we see the observed TPI from HadISST and ERA5 within the spread of the CAFE60v1 ensemble across the entire record post the initial spinup period 1960-62. After the mid-1990s, there is a reduction in the CAFE60v1 ensemble spread and very good agreement between ERA5, HadISST, and the CAFE60v1 ensemble mean. Also included is the TPI for the ACCESSCM2 and CAFE control simulations. Here it is noticeable that the internal variability of the ACCESS CM2 control TPI and historical simulations is reduced relative to the observations and CAFE60v1 ensemble and control. There are also differences between the CAFE60v1 and ACCESS TPI climatologies (Fig. 10, upper-right panel) with ACCESS generally too warm over August through February.

Schlesinger and Ramankutty (1994) first identified a coherent pattern of variability in basinwide North Atlantic SSTs with a period of about $60-80$ years, which they named the Atlantic multidecadal oscillation (AMO). The AMO has been shown to impact North American climate (Sutton and Hodson 2005), rainfall and river flow (Enfield et al. 2001), the Sahel drought (Rowell et al. 1995), and the frequency and intensity of Atlantic hurricanes (Trenberth and Shea 2006).

The method for calculating the AMO (also known as the Atlantic multidecadal variability or AMV index) is based on the method of Trenberth and Shea (2006) and is used to 

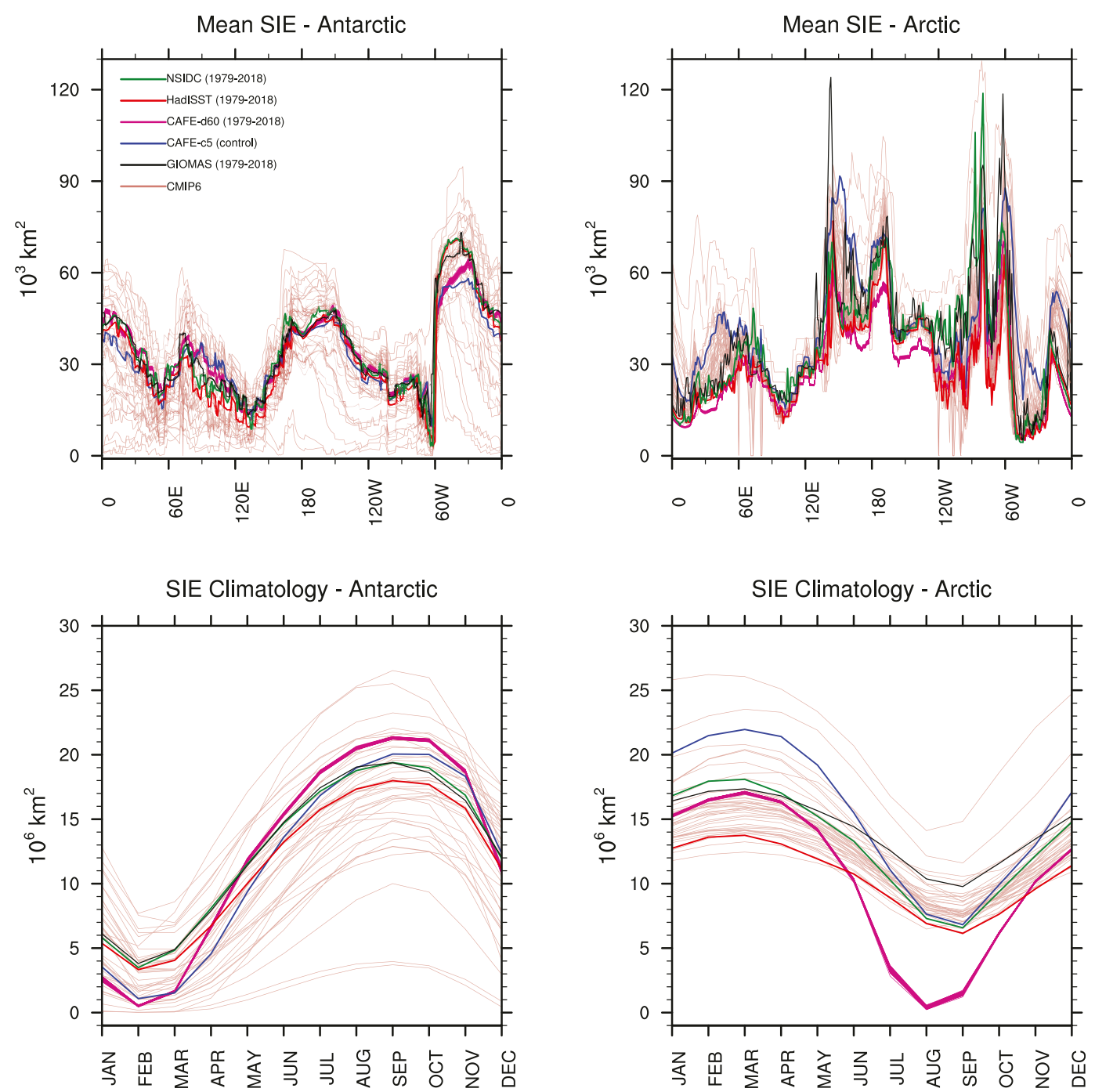

FIG. 8. Sea ice extent (SIE) mean and climatology in observations (GIOMAS, NSIDC, and HadISST), models (control simulation and CMIP6 ensemble), and the CAFE60v1 ensemble members. The CMIP6 models used are listed in supplemental Table 8.

isolate the internal AMO variability from the externally forced component. The AMO index is calculated for North Atlantic $\left(0^{\circ}-60^{\circ} \mathrm{N}\right)$ annual SST anomalies with the global $\left(60^{\circ} \mathrm{N}-60^{\circ} \mathrm{S}\right)$ average removed thereby avoiding deficiencies involving linear trends; this index is then low-pass filtered to remove periods of less than 10 years. A reduced variability in the ACCESS-CM2 projections relative to the reanalysis products is also evident. CAFE60v1 exhibits a large fluctuation during the 1990s with a mean magnitude about twice that of ERA5 and HadISST. After 2000 the reanalyses are in generally close agreement.

\section{b. Property sections}

Zonal and meridional hydrographic sections are selected for assessment of the CAFE60v1 simulation. The decadal mean CAFE60v1 comparison with the 2018 World
Ocean Atlas (Locarnini et al. 2019; Zweng et al. 2019) shows that there is a general decrease in the difference between the CAFE60v1 simulation and the World Ocean Atlas (WOA) between the 1985-94 decade mean to the 2005-17 period (see Figs. $11 \mathrm{a}-\mathrm{f}$ and $12 \mathrm{~g}-\mathrm{j}$ for temperature and supplemental Fig. 4 for salinity). For example, in the 1985-94 decade the Pacific section of the Southern Ocean south of $50^{\circ} \mathrm{S}$ has a subsurface warm difference $\left(>0.5^{\circ} \mathrm{C}\right)$ that is greatly reduced in the latter decade. The reduction in the differences between CAFE60v1 and WOA between the two decadal time periods is not seen at the ocean boundaries and along the equator. At the ocean boundaries and along the equator the ocean circulation is dominated by intense and highly variable narrow currents. Displacement both vertically and horizontally of these features between the CAFE60v1 and WOA would result in 

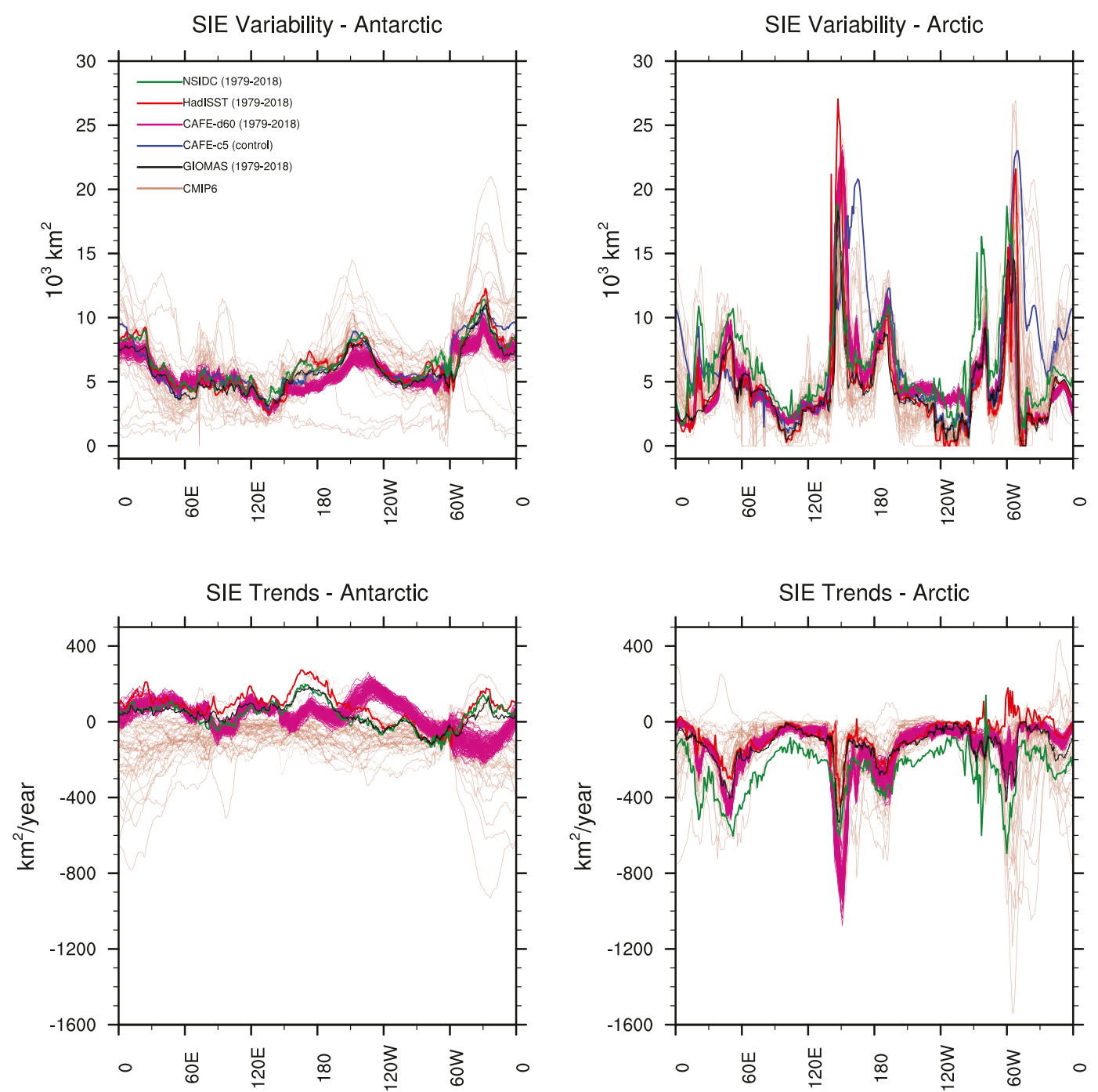

FIG. 9. Sea ice extent (SIE) variability and trends in observations (GIOMAS, NSIDC, and HadISST), models (control simulation and CMIP6 ensemble), and the CAFE60v1 ensemble members. The CMIP6 models used are listed in supplemental Table 8.

large systematic difference in the temperature and salinity sections in these regions. Also the CAFE60v1 horizontal resolution, nominally $1^{\circ}$, and higher resolution at the equator $\left(0.33^{\circ}\right)$ and Southern Ocean $\left(0.25^{\circ}\right)$, while able to resolve the net transport of these narrow currents is not designed to resolve the sharp temperature and salinity gradient associated with these features. Comparable errors of up to $3^{\circ} \mathrm{C}$ along the equator about the $20^{\circ} \mathrm{C}$ isotherm are also noted for NCEP CFSR (Saha et al. 2010, their Fig. 28) relative to the 2005 WOA over the period 1982-2008.

\section{c. Representation of mode water formation regions}

The representation of the near-surface water mass in the CAFE60v1 reanalysis product is assessed by investigation of the model's capacity to represent Mode Water, easily identified by its particular signature of low Ertel potential vorticity
(PV), defined here in terms of the vertical gradient of potential density $\sigma_{\theta}$ :

$$
Q=\frac{f}{\rho_{0}} \frac{\partial \sigma_{\theta}}{\partial z}
$$

where $f$ is the Coriolis parameter and $\rho_{0}$ is the reference density. We have explicitly ignored both the relative vorticity and the nonvertical components of the Ertel PV.

Three regions known to be strong mode water formation regions are chosen for investigation: the central North Atlantic (known for the production of 18 Degree Water) near $55^{\circ} \mathrm{W}$ longitude, the central South Pacific near $90^{\circ} \mathrm{W}$ longitude, and in the South Indian basin near $100^{\circ} \mathrm{E}$. We plot time means over each 10 -yr period for the month corresponding to the largest volume of mode water, which typically occurs in late winter/early spring. For the South Pacific and South Indian regions, we plot the time 

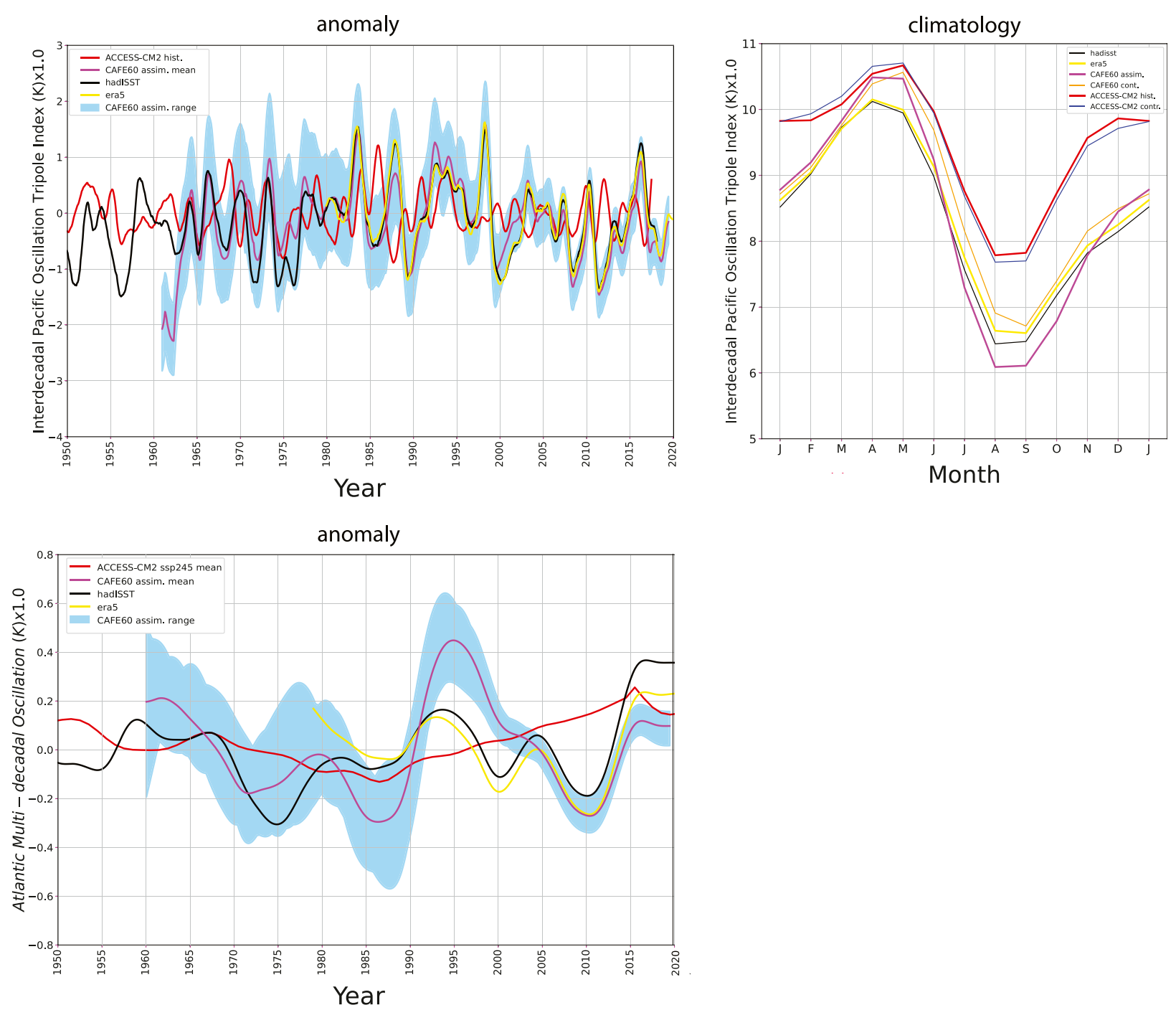

FIG. 10. (top) The interdecadal Pacific oscillation (IPO) in terms of the tripole index (TPI). We compare ACCESS-CM2 historical, ERA5, HadISST, and the CAFE60v1 ensemble. Also included are the ACCESS-CM2 and CAFE control simulations. The left panel shows the variability and the right climatologies. (bottom) Comparison of Atlantic multidecadal oscillation.

mean for September, whereas for the North Atlantic section the February average is shown.

Following Forget et al. (2011), we define mode waters as those waters with a PV of less than $1.5 \times 10^{-10} \mathrm{~s}^{-1} \mathrm{~m}^{-1}$. This threshold is indicated in Fig. 13 as dashed lines (black for the CAFE60v1 reanalysis, white for the WOA) to allow easy comparison between the modeled and observed water mass structure. Here we show the two most recent WOA decades 1995-2004 and 2005-17 with results for all decades between 1965 and 2017 displayed in supplemental Fig. 5. The lack of observations prior to the most recent decade is clearly evident in the WOA PV minimum and reflects a high degree of uncertainty in the observed mode water structure. In all regions studied here, the CAFE60v1 reanalysis reproduces the basic structure of the water masses seen in observations, with a tongue of low PV water (indicative of mode water) reaching depths of nearly $400 \mathrm{~m}$ in the North Atlantic and $600 \mathrm{~m}$ in the south Indian and South
Pacific Oceans. Over the 2005-17 period, in the North Atlantic, the CAFE60v1 reanalysis underestimates the depth and volume of the mode waters when compared with the WOA derived estimate. For the south Indian and South Pacific locations the converse is true: CAFE60v1 overestimates the mode water volume and its depth when compared with WOA. The absolute biases are higher in both these regions than in the North Atlantic, although we note that this bias would be reduced by increasing the PV threshold criteria used to define mode water.

The mode water structure produced by CAFE60v1 is substantially the same in the 1995-2004 and 2005-17 time periods. Only modest bias reductions in the depth of the PV minimum and volume of the mode water are observed over the recent two decades where WOA PV is relatively well resolved. As such, it appears that the increase in assimilated subsurface observations in the 2005-17 period does not strongly reduce the mode water biases in the state 

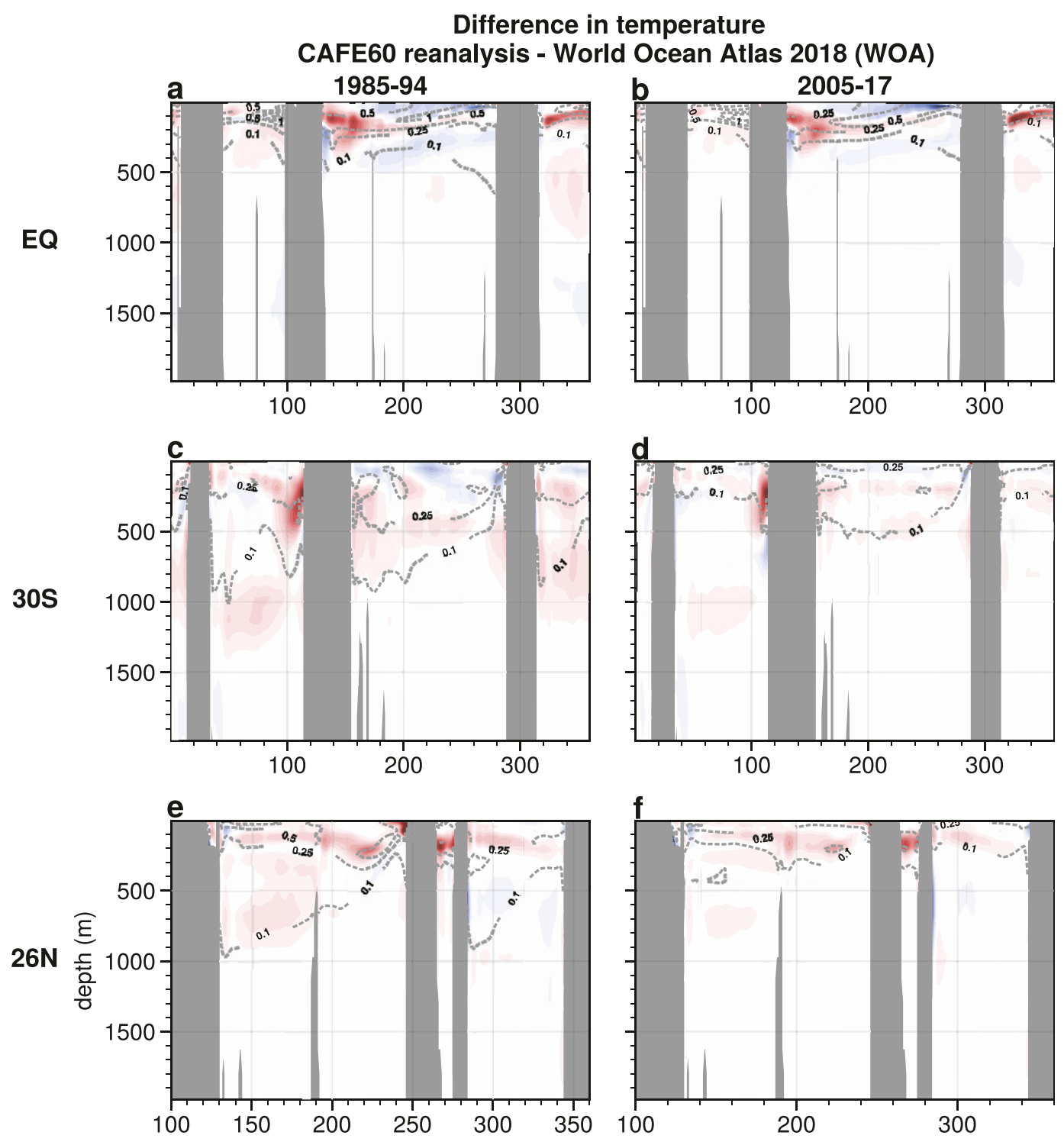

longitude

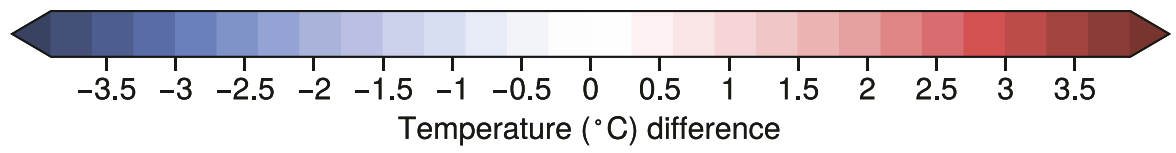

FIG. 11. Differences between CAFE60v1 and WOA averaged over the decades 1985-94 and 2005-17 for temperature sections along the equator, $30^{\circ} \mathrm{S}$ and $26^{\circ} \mathrm{N}$. Note the corresponding salinity sections are in supplemental Fig. 4.

estimate, although there is some indication of improvement in the overall water mass structure in the south Indian region. Regardless, state estimation of mode waters is challenging due to a reliance on accurate estimates of salinity where even small model biases can have significant impact on estimates of the PV minima.

\section{d. Meridional overturning streamfunction and transports}

The global meridional overturning circulation (MOC) consists of the shallow tropical wind-driven cells, the Deacon cell driven by the Southern Hemisphere subpolar westerlies, the Antarctic Bottom Water (AABW) cell south of $60^{\circ} \mathrm{S}$, the Southern Ocean abyssal cell (here referred to as SOAC), and the North Atlantic Deep Water (NADW) cell. For an overview of the global overturning circulation and inverse based transport estimates we refer to Lumpkin and Speer (2007).

The MOC is defined using the streamfunction $\psi$ in units of Sverdrups $\left(1 \mathrm{~Sv}=10^{6} \mathrm{~m}^{3} \mathrm{~s}^{-1}\right.$ or approximately $\left.10^{9} \mathrm{~kg} \mathrm{~s}^{-1}\right)$. It is 


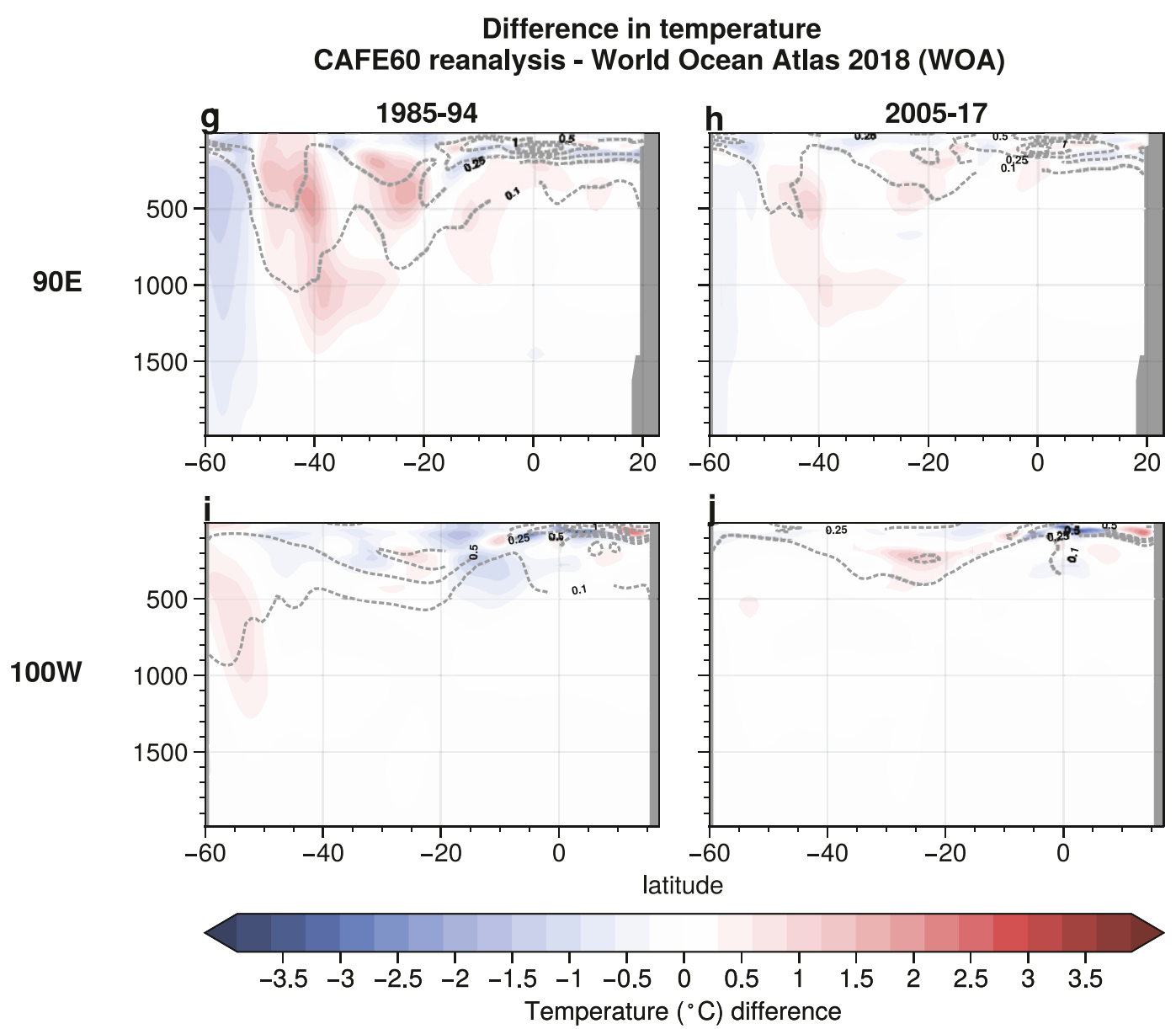

FIG. 12. Differences between CAFE60v1 and WOA averaged over the decades 1985-94 and 2005-17 for temperature sections along $90^{\circ} \mathrm{E}$ and $100^{\circ} \mathrm{W}$. Note the corresponding salinity sections are in supplemental Fig. 4 .

the zonally integrated and vertically accumulated meridional volume transport in depth coordinates as defined as

$$
\psi(z)=\int_{z}^{o} \int_{x_{w}}^{x_{e}} v\left(x, z^{\prime}\right) d x d z^{\prime}
$$

CAFE60v1 generates mass transport $\left(\mathrm{kg} \mathrm{s}^{-1}\right)$ as a function of horizontal location and depth, and so these can be used in place of volume in Eq. (2) to generate a MOC in the preferred mass units. To obtain transports for the MOCs in a basin defined as a function of depth and latitude, the full depth model mass transports are used and integrated between east and west boundaries (coast to coast). It is therefore possible to define them globally, for the Atlantic (north of the southern tip of Africa) and Arctic combined, and for the Indian and Pacific Oceans combined. The latter cannot be separated normally as there is mass transfer via the Indonesian Passage.

To obtain strength of overturning for a particular common index and to compare to generally very limited observations, we follow Bi et al. (2013) and simply identify the maximum value within a particular depth and latitude box. The ranges of these boxes are as follows:
- North Atlantic Deep Water (NADW) $30^{\circ}-50^{\circ} \mathrm{N}, 500$ $3000 \mathrm{~m}$;

- Atlantic Meridional Overturning Streamfunction (AMOC26 $6^{\circ}$ ) $25.5^{\circ}-26.5^{\circ}, 0-6000 \mathrm{~m}$;

- Antarctic Bottom Water (AABW) 90-60요 0-3000 m;

- Southern Ocean Abyssal Cell (SOAC) 60-20 S, 3000$6000 \mathrm{~m}$.

Note that $\mathrm{AMOC} 26^{\circ} \mathrm{N}$ is identified at the two longitudes $25.5^{\circ}$ and $26.5^{\circ} \mathrm{N}$ that span the required $26^{\circ} \mathrm{N}$. While the recent study of Leroux et al. (2018) investigated the origin and features of interannual-decadal AMOC variability from a large (50 member) randomly perturbed ensemble of forced global, eddy-permitting $1 / 4^{\circ}$ ocean-sea ice hindcasts, the subsurface ocean was not initialized to observations. In this respect, the CAFE60v1 large ensemble offers unprecedented sampling of multiyear to decadal variability of the structure and variability of the MOC.

Given the sparse and highly uncertain observation-based estimates of the MOC, with the exception of RAPID-based AMOC estimates, in the results to follow, the CAFE60v1 ensemble mean is again compared to ACCESS-CM2 CMIP6 


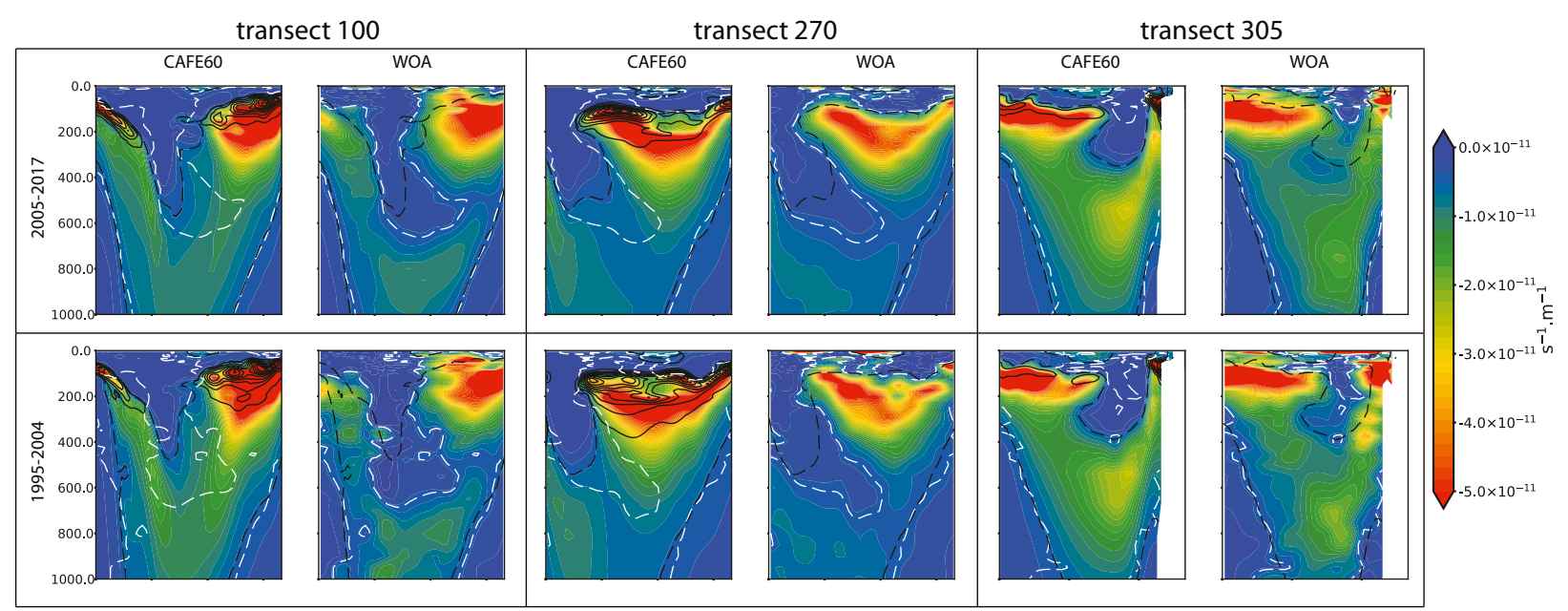

FIG. 13. Transects (vertical, stretching component) of the September Ertel PV along $100^{\circ} \mathrm{E}$ (south Indian Ocean), $270^{\circ} \mathrm{E}(\mathrm{central}$ Pacific), and $305^{\circ} \mathrm{E}$ (North Atlantic) for the decades 1995-2004 and 2005-17. Colors are the ensemble mean time mean PV; thick solid contours are the time mean ensemble standard deviation of PV. The white dashed line indicates the observational time mean PV minima (indicative of mode water); the black line indicates the equivalent model PV minima.

historical and control simulations (two realizations). Specifically, monthly climatologies are computed for ACCESS-CM2 historical (2 member average) and CAFE60v1 assimilation (96 member average) experiments using the years 1980-2010 inclusive. Monthly climatologies are computed for the single control experiments using the 30 inclusive years in the periods 1420-49 and 2070-99, respectively. Monthly anomalies for all four experiments (ACCESS-CM2 control and historical, and CAFE60v1 control and assimilation) are formed from the above mentioned climatologies for all available model years. We compare the global (Fig. 14), Atlantic-Arctic (Fig. 15), and Indo-Pacific (supplemental Fig. 6) MOCs from two periods, one pre-Argo (1970-80) and for the most recent decade (2008-18), and the difference between these periods. Transports of the relevant cells and for important exchange regions are shown in Fig. 16 over the last six decades and for the CAFE and ACCESS-CM2 control model simulations.

The CAFE60v1 NADW intensity averages around $17 \mathrm{~Sv}$ (supplemental Fig. 7) whereas observed values range about 15 Sv (Lumpkin et al. 2008; Ganachaud 2003). The AMOC cell has an estimated observed transport from 2004 to 2012 of 17.2 Sv at $26^{\circ} \mathrm{N}$ (McCarthy et al. 2015). The CAFE60v1 AMOC $26^{\circ} \mathrm{N}$ (Fig. 16) is within the observed range of seasonal variations between 10 and $25 \mathrm{~Sv}$ from the RAPID-WATCH observation (Smeed et al. 2015) and matches the observed variability closely over the most recent decade. The CAFE60v1 AMOC cell penetrates deeper than the modeled ACCESS-CM2 and is hence somewhat more realistic (Fig. 15). The abyssal overturning cell (the negative cell and a significant fraction of global water volume) has rough observation-based estimates of between 20 and $50 \mathrm{~Sv}$ (Sloyan and Rintoul 2001; Lumpkin and Speer 2007; Talley 2013) but here in CAFE60v1, as with many models, is too weak. The difference between the two periods is small (MOC) or indicate a slight weakening (AMOC) for the ACCESS-CM2 historical simulations, which have an overall too strong upper positive cell. For CAFE60v1 and consistent with the RAPID time series, the indication is that the AMOC has strengthened over the last decade but that this strengthening is no greater than the decadal variability (Fig. 16).

In the Southern Ocean, the AABW cell (supplemental Fig. 7) evolves with a range from 5 to $10 \mathrm{~Sv}$, but averages to close to the value reported by Lumpkin and Speer (2007) of $5.6 \pm 3.0 \mathrm{~Sv}$ but somewhat less than the observed values reported by Sloyan and Rintoul (2001), Garabato et al. (2002), and Talley (2013), who diagnosed AABW formation values of $9.77 \pm 3.7 \mathrm{~Sv}$ in the Weddell Sea (Fig. 16). The CAFE60v1 SOAC transport (supplemental Fig. 7) averages $19 \mathrm{~Sv}$ and is at the upper range of values reported for CORE forced ocean simulations (Bi et al. 2013). Drake Passage transport (Fig. 16) is a proxy for the strength of the Antarctic Circumpolar Circulation (ACC). Here the Drake Passage time series has been calculated from CAFE60v1 monthly averaged 3D ocean horizontal mass transports where the eastward component is integrated along a single line from the southern tip of South America to the northern tip of the Antarctic Peninsula and to the ocean bottom. Here the simulated ACC strength is between 180 and $190 \mathrm{~Sv}$ in ACCESS-CM2 and averages to around $150 \mathrm{~Sv}$ in the CAFE control with similar strength in CAFE60v1 but with evident decadal variations in the reanalysis. Estimates of the observed Drake Passage transport values range between $134 \pm 13 \mathrm{~Sv}$ (Whitworth and Peterson 1985) and $173 \mathrm{~Sv}$ (Donohue et al. 2016).

Recent work (Jochum and Eden 2015; Newsom and Thompson 2018) has shown the importance of surface processes at the low latitudes of the Indo-Pacific Ocean in determining the strength and structure of the global overturning circulation. Hence the processes occurring at the equatorial Indo-Pacific Ocean surface are of increased importance to the overturning relative to what was previously assumed. The 

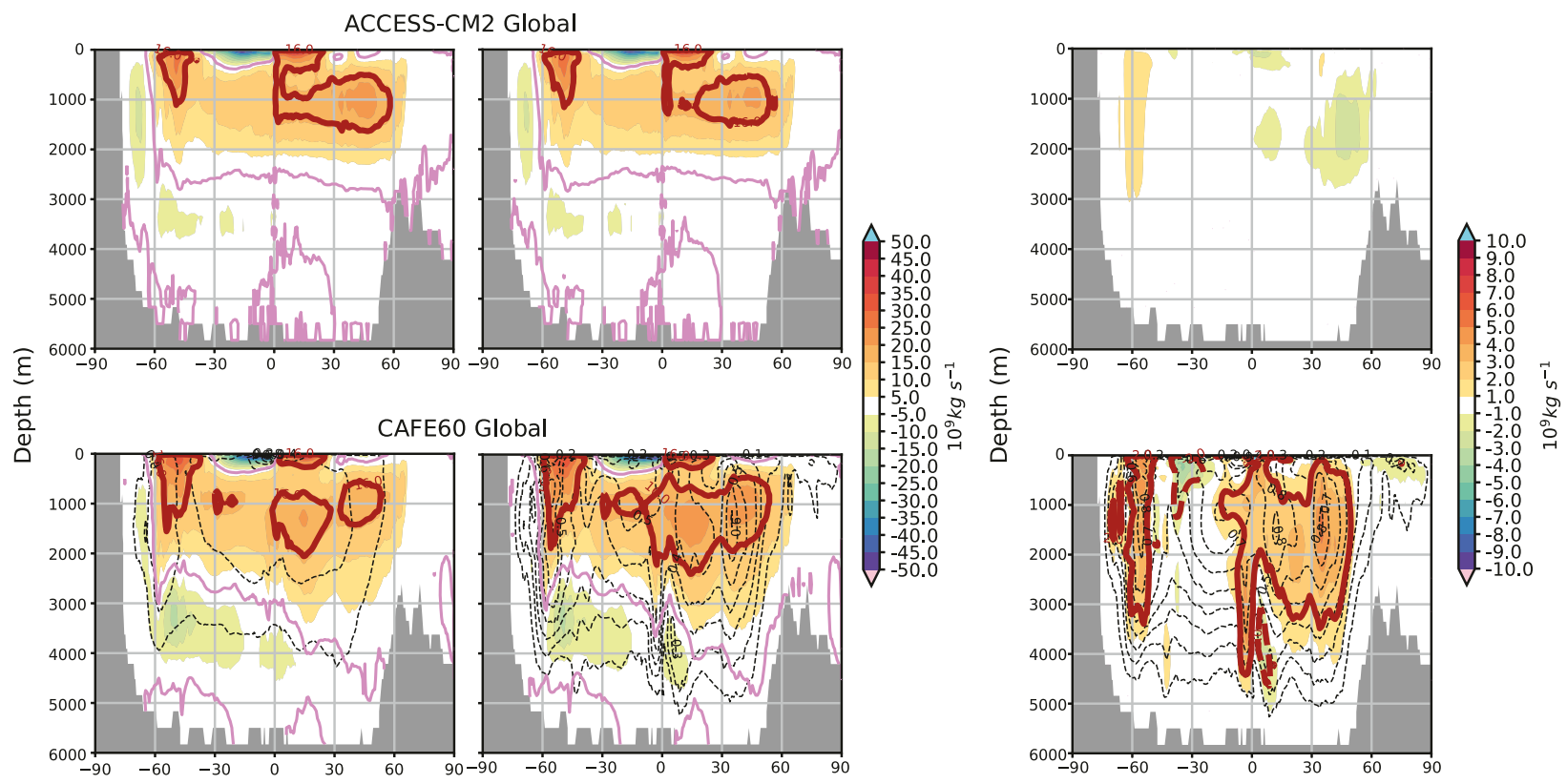

FIG. 14. ACCESS-CM2 and CAFE60v1 meridional volume transport in depth coordinates defined in terms of the mass transport $\left(\mathrm{kg} \mathrm{s}^{-1}\right)$ as a function of horizontal location and depth. Here the MOC is defined globally. The solid red contours indicate $16 \mathrm{~Sv}$ in the $\mathrm{MOC}$ and $\pm 2 \mathrm{~Sv}$ in the difference plots, respectively.

CAFE60v1 Indo-Pacific MOC (supplemental Fig. 6) has welldefined upper $(0-3000 \mathrm{~m})$ and lower $(3000-5000 \mathrm{~m})$ cells clearly evident in both the pre-Argo and most recent decades. These structures and strengths are consistent with observations (Fig. 3: Lumpkin and Speer (2007)). In contrast, the positive upper cell is absent in the ACCESS-CM2 simulations.
For the Indonesian Throughflow (ITF; Fig. 16) two lines of eastward components of horizontal mass transports and three lines of northward components are integrated to the ocean bottom, forming a constant line from the southern edge of Borneo south to the main island of Indonesia, through several minor seas resolved in the model, and from the eastern tip of
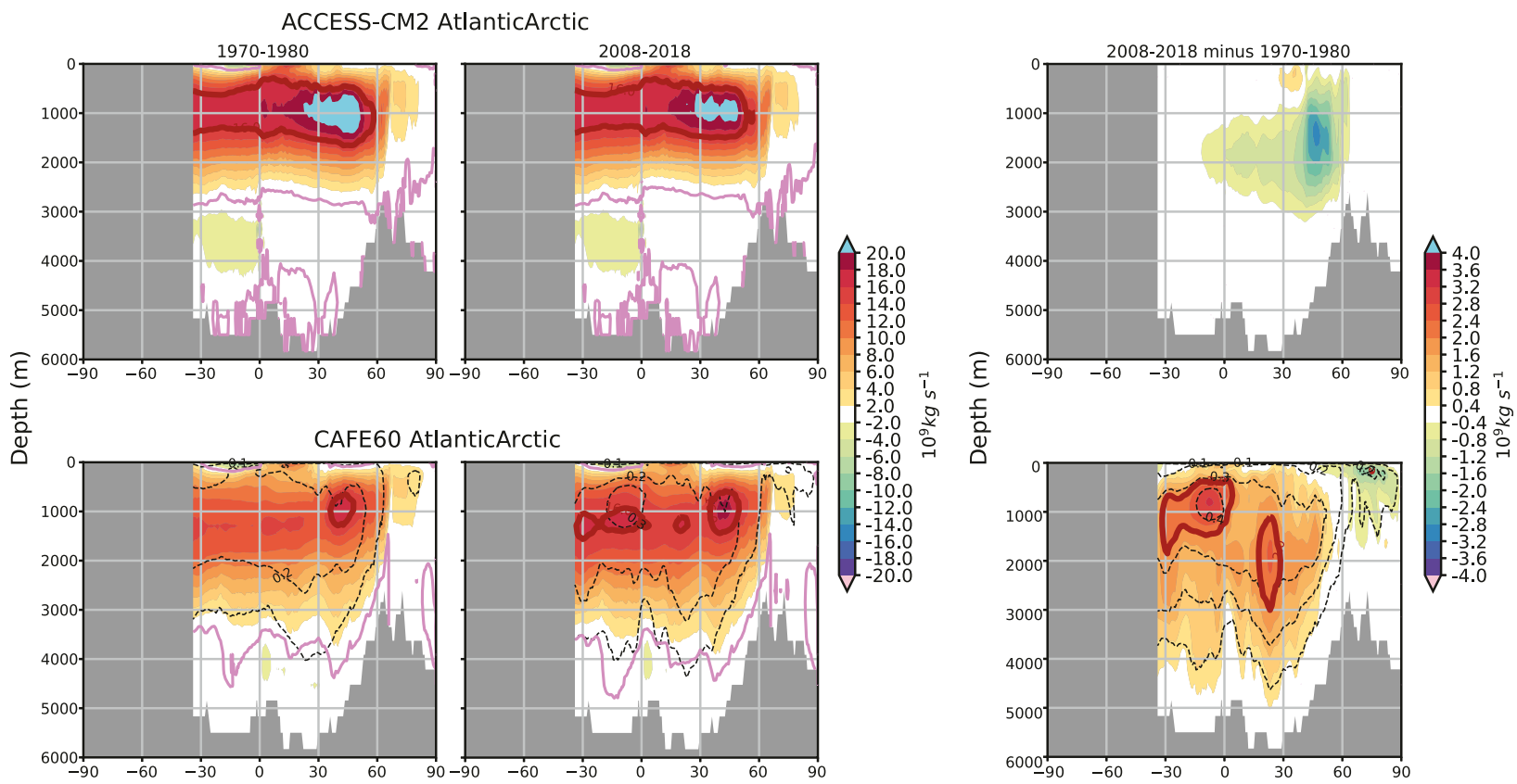

FIG. 15. As in Fig. 14, but here the MOC is defined for the Atlantic (north of the southern tip of Africa) and Arctic combined. 


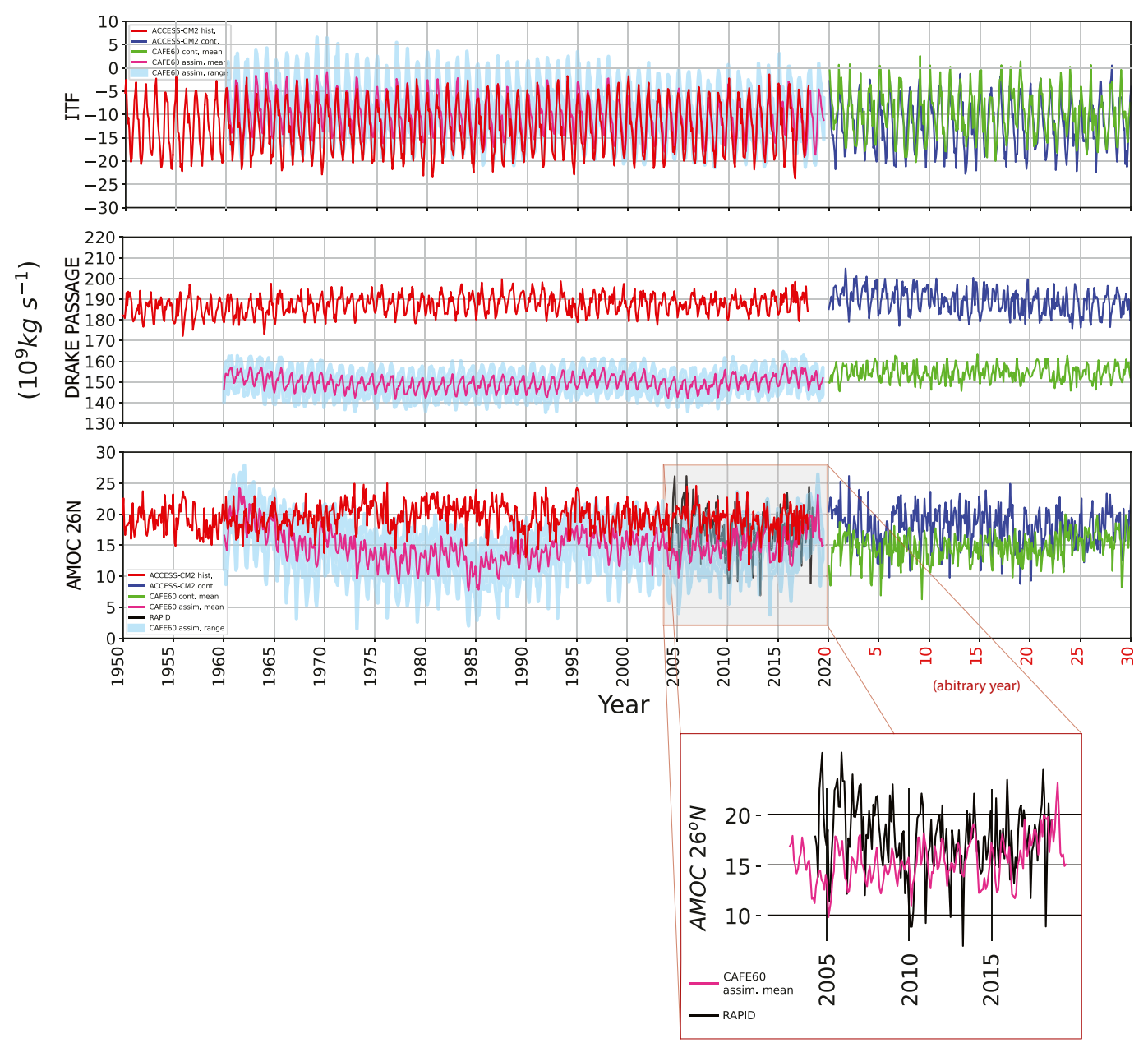

FIG. 16. Time series of transports comparing ACCESS-CM2 (2 member average) and CAFE60v1 (96 member average) for both historical and representative 30-yr segments of their respective control simulations. Simulated transport indices (Sv): (a) Indonesian Throughflow, (b) Drake Passage, and (c) the maximum AMOC transport at $26^{\circ} \mathrm{N}$. The expanded inset panel shows the detailed comparison of CAFE60v1 directly to observations from the RAPID array.

East Timor to the southwestern peninsula of Papua New Guinea. Here we see very close agreement between CAFE60v1 and ACCESS-CM2 mean values of around $10 \mathrm{~Sv}$ relative to early estimates by Meyers et al. (1995) of a maximum net relative transport toward the west between Australia and Indonesia of $12 \mathrm{~Sv}$. However, CAFE60v1 ITF transports are decidedly weaker than the more recent INSTANT observations by Sprintall et al. (2009) and Gordon et al. (2010) of $15 \mathrm{~Sv}$.

\section{Ocean biogeochemistry}

To assess the realism of CAFE60v1 with ocean biogeochemistry (OBGC), we compare the annual anthropogenic dissolved inorganic carbon (ADIC) field with the observedderived total dissolved inorganic carbon (DIC) concentration from the synthesis of in situ observations provided by GLODAPv2 (Lauvset et al. 2016; Olsen et al. 2016). The
GLODAPv2 product has the nominal year of 2002, and we use the annual mean concentration of the CAFE60v1 ensemble mean from this year for comparison. CAFE60v1 broadly captures the large-scale DIC distribution of the GLODAPv2 (Fig. 17). CAFE60v1 has slightly less DIC in the thermocline of the middle and low latitudes and below $500 \mathrm{~m}$ in the Arctic. Below $1000 \mathrm{~m}$, CAFE60v1 has slightly higher DIC concentrations than GLODAPv2.

For the phosphate, CAFE60v1 large-scale distribution is generally consistent with the GLODAPv2 (Lauvset et al. 2016). Like DIC, CAFE60v1 has slightly less phosphate in the upper ocean of the middle and low latitudes, while below $1000 \mathrm{~m}$ it has more phosphate than GLODAPv2 (Fig. 17c). Relative to GLODAPv2, CAFE60v1 tends to shift carbon and nutrients from the upper ocean into the ocean interior.

To assess CAFE60v1 sea-air fluxes of $\mathrm{CO}_{2}$, we first compare its climatological flux from the mean of 1985-2015 to the observationally derived estimate of Landschützer et al. (2016) 



FIG. 17. 2002 Annual mean ADIC (adic). Anthropogenic $\mathrm{CO}_{2}$ (aco2) and phosphate (po4) concentrations: (left) observed as compared to (right) CAFE60.

(Fig. 18). The broad-scale pattern of the fluxes is similar, but there are several interesting differences. In both hemispheres, CAFE60v1 has higher fluxes into the ocean on the polar side of the oligotrophic gyres. The enhanced flux occurs in all western boundary current regions and then extends across the basin. Particularly in the western boundary current regions, the temperature is a dominant driver of the fluxes. As these currents bring the subtropical water poleward it is cooled, and this drives a flux of $\mathrm{CO}_{2}$ into the ocean. In the equatorial regions, CAFE60v1 has less flux of $\mathrm{CO}_{2}$ out of the ocean than the Landschützer et al. (2016) climatological estimate. Similarly, in the Southern Ocean south of the polar front, CAFE60v1 has higher flux out of the ocean than Landschützer et al. (2016) and is more consistent with the recent analysis of Bushinsky et al. (2019) using the Southern Ocean Carbon and Climate Observations and Modeling (SOCCOM) floats. This suggests the $\mathrm{CO}_{2}$ flux out of the Southern Ocean south of the polar front is higher than estimated in climatological products like Landschützer et al. (2016). A more detailed comparison and assessment of CAFE60v1 with the in situ data is needed, and it will be the focus of future work.

From CAFE60v1, we show global and Southern Ocean (south of $35^{\circ} \mathrm{S}$ ) sea-air $\mathrm{CO}_{2}$ flux from both the DIC (natural) and ADIC (total) tracers (Fig. 19). Both time series show CAFE60v1 has an initial transition phase of about a decade where the ocean adjusts to the changes produced by the data assimilation. The natural flux stabilizes to have a global net flux of $\mathrm{CO}_{2}$ into the ocean of about $0.6 \mathrm{PgC} \mathrm{yr}^{-1}$. Such a net flux is consistent with the CAFE60v1 tendency to shift DIC from the upper ocean into the ocean interior. Globally, the standard deviation in the annual flux is about $0.5 \mathrm{PgC}^{-1}$, and the Southern Ocean has about half that $\left(0.25 \mathrm{PgC} \mathrm{yr}^{-1}\right)$. There is a distinct feature in these time series around 1991-93 associated with the Pinatubo eruption where the large flux of $\mathrm{CO}_{2}$ into the ocean is related to volcanic cooling followed by an ocean outgassing as the climate warms. The effect is global, and it is apparent in the Southern Ocean too.

Previous analysis has quantified the interannual variability in the sea-air $\mathrm{CO}_{2}$ fluxes from the sparse observations available (DeVries et al. 2017; Landschützer et al. 2015). Here we compare CAFE60v1 global and Southern Ocean estimates to the Rodenbeck et al. (2013) estimate (Fig. 19). For the global ocean, CAFE60v1 produces similar but slightly higher interannual variability than Rodenbeck et al. (2013). Interestingly, CAFE60v1 has a much greater increasing trend in the $\mathrm{CO}_{2}$ flux into the ocean than Rodenbeck et al. (2013).

The CAFE60v1 anthropogenic $\mathrm{CO}_{2}$ concentration is consistent with the observation derived estimate of GLODAPv2 in both the magnitude and penetration of anthropogenic $\mathrm{CO}_{2}$ into the ocean (Fig. 17). For the column inventory of 
a)

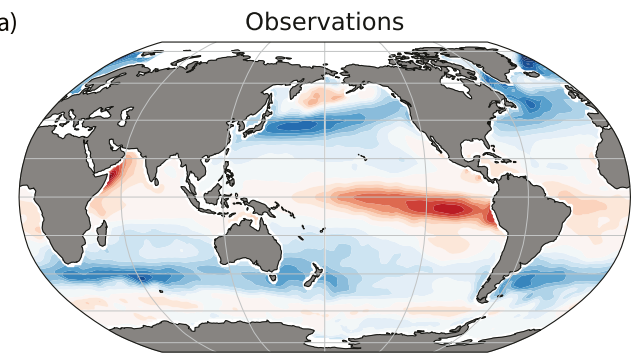

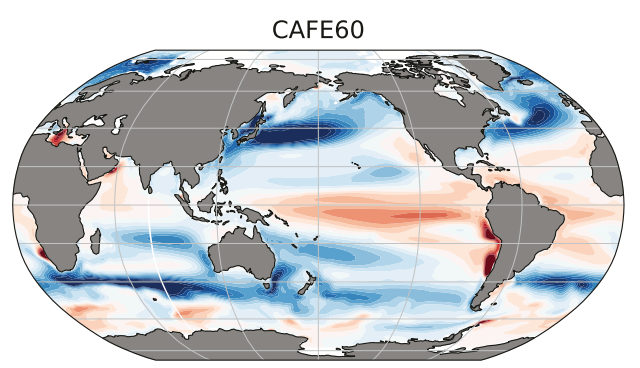

b)
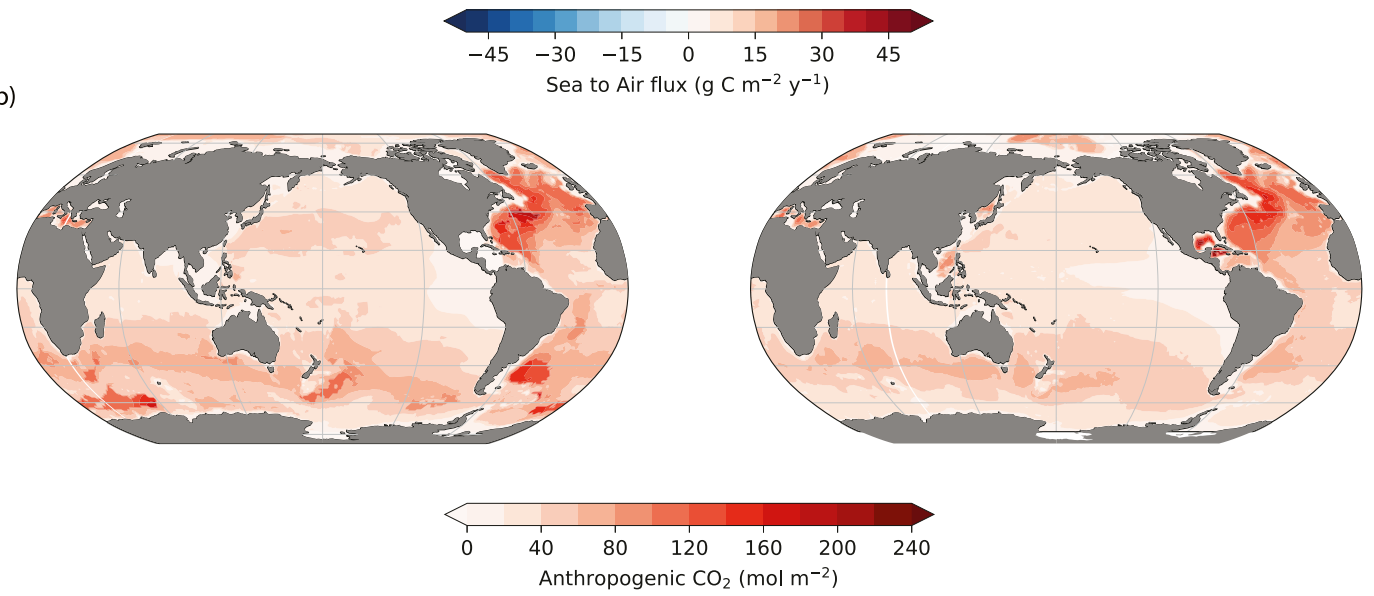

FIG. 18. (a) 1985-2015 annual mean sea-air flux of $\mathrm{CO}_{2}$ (Landschützer et al. 2016): (left) observed and (right) CAFE60v1. (b) The 2002 column inventory of anthropogenic $\mathrm{CO}_{2}$ (left) derived from the observations of Lauvset et al. (2016) and (right) simulated by the CAFE60v1 ensemble mean.

anthropogenic $\mathrm{CO}_{2}$ in the North Atlantic (Fig. 18), CAFE60v1 has elevated values on the west and east sides of the basin with a tongue on the western side of the basin moving into the Southern Hemisphere evident in GLODAPv2. CAFE60v1 has elevated inventories in the Gulf of Mexico where the GLODAPv2 has no data. In the Southern Ocean (Fig. 19), CAFE60v1 has a maximum inventory across the basin between $40^{\circ}$ and $60^{\circ} \mathrm{S}$ like the GLODAPv2. However, CAFE60v1 lacks the prominent highs off Argentina, New Zealand, and in the south Indian Ocean. The tendency of CAFE60v1 to have higher $\mathrm{CO}_{2}$ fluxes into the ocean than recent observation-derived products are not reflected in a corresponding overestimate of the anthropogenic $\mathrm{CO}_{2}$ column inventory.

\section{Summary and conclusions}

We have described the first large ensemble global reanalysis (CAFE60v1) produced at the CSIRO Climate Science Center covering the period from 1960 to the present. As noted by Saha et al. (2010), the accuracy of any climate reanalysis can be hard to assess, particularly given the paucity of subsurface ocean observations prior to Argo. Previously in Part I, we assessed analysis and forecast innovation errors (i.e., differences between analysis, forecast, and observations in observation space). The approach taken here, is to examine the major climate teleconnections, ocean structure and transports, sea ice (extent, concentration, and variability), land surface (temperature and precipitation), and ocean biogeochemistry in comparison to observational estimates, reanalyses, and climate model simulations.

The combined use of SCDA, large ensemble size, and assimilation of monthly observations has not been attempted before. Some surprising errors were found to occur; most notably, the use of crossdomain covariances in the background ensemble produced unexpected systematic errors in the analysis of Arctic summer sea ice. Furthermore, between 1992 and 2005, the rapid increase in both satellite SST and subsurface temperature observations produced some spurious trends in global ocean temperature and salinity as the largely unconstrained subsurface model ocean state was constrained to observations. Undoubtedly, more errors and or inconsistencies will be discovered in the future, but this should be simply seen in the context of progress toward increasingly improved analyses of Earth's recent climate system. That said, CAFE60v1 has demonstrated that there is utility in application of SCDA, and in particular the constraint of the large-scale atmosphere to be consistent with ocean temperature gradients. Importantly, the large ensemble of state estimates [i.e., $O(100)$ realizations] provides for the first time a self-consistent sample of sufficient size to enable estimation of the mean, variance, and, less accurately, skewness through time.

A primary role of CAFE60v1 was to create initial conditions for operational near-term ensemble climate hindcasts over the period from 1960 and forecasts from the present day. The system is now operational with the reanalysis regularly updated to present and forecasts generated each May and 

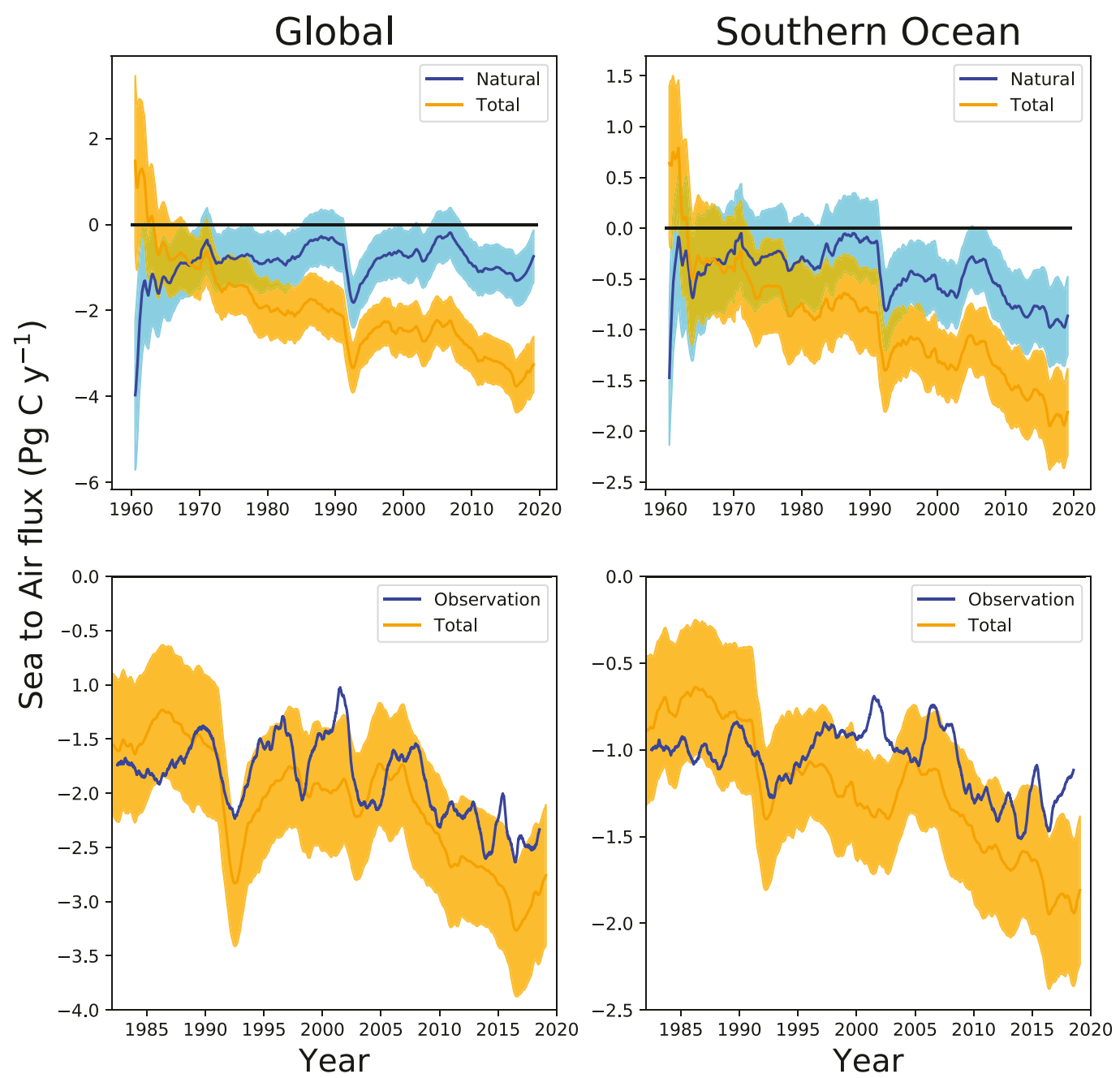

FIG. 19. CAFE60v1 annual sea-air flux of $\mathrm{CO}_{2}$ for (left) the global ocean and (right) the Southern Ocean south of $35^{\circ} \mathrm{S}$. In the panels, the solid lines are the ensemble mean and the shading is the standard deviation of the ensemble. (top) The CAFE60v1 total flux and the CAFE60v1 flux associated with the simulated natural DIC tracer. (bottom) CAFE60v1 total flux and observational derived product from Rodenbeck et al. (2013).

November. Building on the numerous insights learned from CAFE60v1, a next-generation system is currently being developed featuring major improvements across a number of fronts-in particular, improved sea ice via assimilation of satellite thickness observations, assimilation of chlorophyll A and carbon observations, the assimilation of remotely sensed soil moisture observations, and joint state and parameter estimation for reduced biases in surface fluxes and ocean mixing (Kitsios et al. 2021).

The CAFE60v1 reanalysis will be publicly available for download from June 2021 at the following URL: http:// hdl.handle.net/102.100.100/389002.

Acknowledgments. The authors were supported by the Australian Commonwealth Scientific and Industrial Research Organisation (CSIRO) Decadal Climate Forecasting Project (https://research.csiro.au/dfp). We gratefully acknowledge the support of National Computing Infrastructure (NCI) Australia and the Pawsey Supercomputing Centre. We appreciate support from Stephen Griffies and Naishali Naik at NOAA GFDL in providing the CM2.1 model codes and radiative forcing data. Data from the RAPID MOC monitoring project are funded by the Natural Environment Research Council and are freely available (https://www.rapid.ac.uk/rapidmoc). GLODAP (https:// www.glodap.info/index.php/data-access/) and WOA (https:// www.nodc.noaa.gov/OC5/woa18/woa18data.html) data are also freely available. We acknowledge the World Climate Research Programme, which, through its Working Group on Coupled Modelling, coordinated and promoted CMIP6. We thank the observing community for their commitment to maintaining a sustained Earth observing system. We thank the climate modeling groups for producing and making available their model output, the Earth System Grid Federation (ESGF) for archiving the data and providing access, and the multiple 
funding agencies who support CMIP6 and ESGF (https://wcrpcmip.github.io/CMIP6_CVs/docs/CMIP6_source_id.html). We acknowledge ERSSTv5 data from NOAA National Centers for Environmental Information (https://doi.org/10.7289/ V5T72FNM), SST data (HadISST v1.1 retrieved from https:// climatedataguide.ucar.edu/climate-data/sst-data-hadisst-v11), and the National Snow and Sea Ice Data Center (https://nsidc.org/). Finally, we especially thank the editor and two anonymous reviewers for their guidance and thoughtful comments in preparing this manuscript for publication.

\section{REFERENCES}

Adames, Á. F., and J. M. Wallace, 2014: Three-dimensional structure and evolution of the MJO and its relation to the mean flow. J. Atmos. Sci., 71, 2007-2026, https://doi.org/10.1175/JAS-D-13-0254.1.

Adler, R. F., and Coauthors, 2018: The Global Precipitation Climatology Project (GPCP) monthly analysis (new version 2.3) and a review of 2017 global precipitation. Atmosphere, 9 , 138, https://doi.org/10.3390/atmos9040138.

Alves, O., M. A. Balmaseda, D. Anderson, and T. Stockdale, 2004: Sensitivity of dynamical seasonal forecasts to ocean initial conditions. Quart. J. Roy. Meteor. Soc., 130, 647-667, https:// doi.org/10.1256/qj.03.25.

Balmaseda, M. A., K. Mogensen, and A. T. Weaver, 2013: Evaluation of the ECMWF Ocean Reanalysis System ORAS4. Quart. J. Roy. Meteor. Soc., 139, 1132-1161, https:// doi.org/10.1002/qj.2063.

Barnston, A. G., and R. E. Livezey, 1987: Classification, seasonality, and persistence of low-frequency atmospheric circulation patterns. Mon. Wea. Rev., 115, 1083-1126, https://doi.org/ 10.1175/1520-0493(1987)115<1083:CSAPOL>2.0.CO;2.

Bi, D., and Coauthors, 2013: ACCESS-OM: The ocean and sea-ice core of the ACCESS coupled model. Aust. Meteor. Oceanogr. $J ., 63,213-232$, https://doi.org/10.22499/2.6301.014.

$\mathrm{CM} 2$, the new generation Australian Community Climate and Earth System Simulator Coupled Model. J. South. Hemisphere Earth Syst. Sci., 70, 225-251, https://doi.org/10.1071/ES19040.

BoM, 2019: Australian gridded climate data (AGCD)/AWAP; v1.0.0 snapshot (1900-01-01 to 2018-12-31). Australian Bureau of Meteorology, accessed 2020, https://doi.org/10.4227/166/ $5 \mathrm{a} 8647 \mathrm{~d} 1 \mathrm{c} 23 \mathrm{e} 0$.

Bushinsky, S. M., and Coauthors, 2019: Reassessing southern ocean air-sea $\mathrm{CO}_{2}$ flux estimates with the addition of biogeochemical float observations. Global Biogeochem. Cycles, 33, 13701388, https://doi.org/10.1029/2019GB006176.

Carton, J. A., G. A. Chepurin, and L. Chen, 2018: SODA3: A new ocean climate reanalysis. J. Climate, 31, 6967-6983, https:// doi.org/10.1175/JCLI-D-18-0149.1.

Chen, X., and J. M. Wallace, 2015: ENSO-like variability: 19002013. J. Climate, 28, 9623-9641, https://doi.org/10.1175/JCLID-15-0322.1.

Compo, G., and Coauthors, 2011: The Twentieth Century ReAnalysis Project. Quart. J. Roy. Meteor. Soc., 137, 1-28, https:// doi.org/10.1002/qj.776.

Davini, P., and C. Cagnazzo, 2014: On the misinterpretation of the North Atlantic Oscillation in CMIP5 models. Climate Dyn., 43, 1497-1511, https://doi.org/10.1007/s00382-013-1970-y. , and F. D'Andrea, 2016: Northern Hemisphere atmospheric blocking representation in global climate models: Twenty years of improvements? J. Climate, 29, 8823-8840, https:// doi.org/10.1175/JCLI-D-16-0242.1.
DeVries, T., M. Holzer, and F. Primeau, 2017: Recent increase in oceanic carbon uptake driven by weaker upper-ocean overturning. Nature, 542, 215-218, https://doi.org/10.1038/ nature21068.

Donohue, K. A., K. L. Tracey, D. R. Watts, M. P. Chidichimo, and T. K. Chereskin, 2016: Mean Antarctic Circumpolar Current transport measured in Drake Passage. Geophys. Res. Lett., 43, 11 760-11 767, https://doi.org/10.1002/2016GL070319.

Enfield, D. B., A. M. Mestas-Nunez, and P. J. Trimble, 2001: The Atlantic multidecadal oscillation and its relation to rainfall and river flows in the continental U.S. Geophys. Res. Lett., 28, 2077-2080, https://doi.org/10.1029/2000GL012745.

Fedorov, A. V., and S. G. Philander, 2000: Is El Niño changing? Science, 288, 1997-2002, https://doi.org/10.1126/science.288.5473.1997.

Forget, G., G. Maze, M. Buckley, and J. Marshall, 2011: Estimated seasonal cycle of North Atlantic Eighteen Degree Water volume. J. Phys. Oceanogr., 41, 269-286, https://doi.org/ 10.1175/2010JPO4257.1.

— J. M. Campin, P. Heimbach, C. N. Hill, R. M. Ponte, and C. Wunsch, 2015: ECCO version 4: An integrated framework for non-linear inverse modeling and global ocean state estimation. Geosci. Model Dev., 8, 3071-3104, https://doi.org/ 10.5194/gmd-8-3071-2015.

Ganachaud, A., 2003: Large-scale mass transports, water mass formation, and diffusivities estimated from World Ocean Circulation Experiment (WOCE) hydrographic data. J. Geophys. Res., 108, 3213, https://doi.org/10.1029/2002JC001565.

Garabato, A. C. N., E. L. McDonagh, D. P. Stevens, K. J. Heywood, and R. J. Sanders, 2002: On the export of Antarctic Bottom Water from the Weddell Sea. Deep-Sea Res. II, 49, 4715-4742, https://doi.org/10.1016/S0967-0645(02)00156-X.

Gelaro, R., and Coauthors, 2017: The Modern-Era Retrospective Analysis for Research and Applications, version 2 (MERRA2). J. Climate, 30, 5419-5454, https://doi.org/10.1175/JCLI-D16-0758.1.

Giese, B., S. Urizar, and N. Fuckar, 2002: Southern Hemisphere origins of the 1976 climate shift. Geophys. Res. Lett., 29, 1014, https://doi.org/10.1029/2001GL013268.

Gillett, N. P., T. D. Kell, and P. D. Jones, 2006: Regional climate impacts of the Southern Annular Mode. Geophys. Res. Lett., 33, L23704, https://doi.org/10.1029/2006GL027721.

Gordon, A. L., and Coauthors, 2010: The Indonesian throughflow during 2004-2006 as observed by the INSTANT program. Dyn. Atmos. Oceans, 50, 115-128, https://doi.org/10.1016/ j.dynatmoce.2009.12.002.

Henley, B. J., J. Gergis, D. J. Karoly, S. Power, J. Kennedy, and C. K. Folland, 2015: A tripole index for the interdecadal Pacific oscillation. Climate Dyn., 45, 3077-3090, https:// doi.org/10.1007/s00382-015-2525-1.

Hersbach, H., and Coauthors, 2020: The ERA5 global reanalysis. Quart. J. Roy. Meteor. Soc., 146, 1999-2049, https://doi.org/ 10.1002/qj.3803.

Huang, B., and Coauthors, 2017: Extended Reconstructed Sea Surface Temperature version 5 (ERSSTv5): Upgrades, validations, and intercomparisons. J. Climate, 30, 8179-8205, https://doi.org/10.1175/JCLI-D-16-0836.1.

Hurrell, J. W., 1995: Decadal trends in the North Atlantic Oscillation: Regional temperatures and precipitation. Science, 269, 676-679, https://doi.org/10.1126/science.269.5224.676.

Jochum, M., and C. Eden, 2015: The connection between Southern Ocean winds, the Atlantic meridional overturning circulation, and Indo-Pacific upwelling. J. Climate, 28, 9250-9257, https:// doi.org/10.1175/JCLI-D-15-0263.1. 
Kalnay, E., and Coauthors, 1996: The NCEP/NCAR 40Year Re-Analysis Project. Bull. Amer. Meteor. Soc., 77, 437-471, https://doi.org/10.1175/1520-0477(1996)077<0437: TNYRP $>2.0 . C O ; 2$.

Kitsios, V., T. J. O'Kane, and N. Zagar, 2019: A reduced-order representation of the Madden-Julian oscillation based on reanalyzed normal mode coherences. J. Atmos. Sci., 76, 24632480, https://doi.org/10.1175/JAS-D-18-0197.1.

— , P. Sandery, T. J. O'Kane, and R. Fiedler, 2021: Ensemble Kalman filter parameter estimation of ocean optical properties for reduced biases in a coupled general circulation model. J. Adv. Model. Earth Syst., 13, e2020MS002252, https://doi.org/ 10.1029/2020MS002252.

Kobayashi, S., and Coauthors, 2015: The JRA-55 reanalysis: General specifications and basic characteristics. J. Meteor. Soc. Japan, 93, 5-48, https://doi.org/10.2151/jmsj.2015-001.

Kosaka, Y., and S.-P. Xie, 2013: Recent global-warming hiatus tied to equatorial Pacific surface cooling. Nature, 501, 403-407, https://doi.org/10.1038/nature12534.

Laloyaux, P., and Coauthors, 2018: A coupled reanalysis of the twentieth century. J. Adv. Model. Earth Syst., 10, 1172-1195, https://doi.org/10.1029/2018MS001273.

Landschützer, P., and Coauthors, 2015: The reinvigoration of the Southern Ocean carbon sink. Science, 349, 1221-1224, https:// doi.org/10.1126/science.aab2620.

— , N. Gruber, and D. C. E. Bakker, 2016: Decadal variations and trends of the global ocean carbon sink. Global Biogeochem. Cycles, 30, 1396-1417, https://doi.org/10.1002/2015GB005359.

Lau, K. M., P. J. Sheu, and I. S. Kang, 1994: Multiscale lowfrequency circulation modes in the global atmosphere. J. Atmos. Sci., 51, 1169-1193, https://doi.org/10.1175/15200469(1994)051<1169:MLFCMI>2.0.CO;2.

Lauvset, S. K., and Coauthors, 2016: A new global interior ocean mapped climatology: The $1^{\circ} \times 1^{\circ}$ GLODAP version 2. Earth Syst. Sci. Data, 8, 325-340, https://doi.org/10.5194/essd-8-325-2016.

Leroux, S., T. Penduff, L. Bessieres, J. M. Molines, J.-M. Brankart, G. Serazin, B. Barnier, and L. Terray, 2018: Intrinsic and atmospherically forced variability of the AMOC: Insights from a large-ensemble ocean hindcast. J. Climate, 31, 1183-1203, https://doi.org/10.1175/JCLI-D-17-0168.1.

Locarnini, R. A., and Coauthors, 2019: Temperature. Vol. 1, World Ocean Atlas 2018, NOAA Atlas NESDIS 81, 52 pp.

Lou, J., N. J. Holbrook, and T. J. O'Kane, 2019: South Pacific decadal climate variability and potential predictability. J. Climate, 32, 6051-6069, https://doi.org/10.1175/JCLI-D-18-0249.1.

Lumpkin, R., and K. Speer, 2007: Global ocean meridional overturning. J. Phys. Oceanogr., 37, 2550-2562, https://doi.org/ 10.1175/JPO3130.1.

- - — , and K. Koltermann, 2008: Transport across $48^{\circ} \mathrm{N}$ in the Atlantic Ocean. J. Phys. Oceanogr., 38, 733-752, https:// doi.org/10.1175/2007JPO3636.1.

Madden, R. A., and P. R. Julian, 1971: Detection of a 40-50 day oscillation in the zonal wind in the tropical Pacific. J. Atmos. Sci., 28, 702-708, https://doi.org/10.1175/1520-0469(1971) 028<0702:DOADOI $>2.0 . C O ; 2$.

Mantua, N. J., S. R. Hare, Y. Zhang, J. M. Wallace, and R. C. Francis, 1997: A Pacific interdecadal climate oscillation with impacts on salmon production. Bull. Amer. Meteor. Soc., 78, 1069-1080, https://doi.org/10.1175/1520-0477(1997)078<1069: APICOW $>2.0 . \mathrm{CO} ; 2$.

McCarthy, G., and Coauthors, 2015: Measuring the Atlantic meridional overturning circulation at $26^{\circ}$ N. Prog. Oceanogr., 130, 91-111, https://doi.org/10.1016/j.pocean.2014.10.006.
McGregor, S., A. Sen Gupta, N. J. Holbrook, and S. Power, 2009: The modulation of ENSO variability in CCSM3 by extratropical Rossby waves. J. Climate, 22, 5839-5853, https:// doi.org/10.1175/2009JCLI2922.1.

Meyers, G., R. J. Bailey, and A. P. Worby, 1995: Geostrophic transport of Indonesian throughflow. Deep-Sea Res. I, 42, 1163-1174, https://doi.org/10.1016/0967-0637(95)00037-7.

—, P. McIntosh, L. Pigot, and M. Pook, 2007: The years of El Niño, La Niña, and interactions with the tropical Indian Ocean. J. Climate, 20, 2872-2880, https://doi.org/10.1175/ JCLI4152.1.

Mo, K. C., 2000: Relationships between low-frequency variability in the Southern Hemisphere and sea surface temperature anomalies. J. Climate, 13, 3599-3610, https://doi.org/10.1175/ 1520-0442(2000)013<3599:RBLFVI>2.0.CO;2.

Morice, C. P., J. J. Kennedy, N. A. Rayner, and P. D. Jones, 2012: Quantifying uncertainties in global and regional temperature change using an ensemble of observational estimates: The HadCRUT4 dataset. J. Geophys. Res., 117, D08101, https:// doi.org/10.1029/2011JD017187.

Newsom, E. R., and A. F. Thompson, 2018: Reassessing the role of the Indo-Pacific in the ocean's global overturning circulation. Geophys. Res. Lett., 45, 12 422-12 431, https://doi.org/10.1029/ 2018GL080350.

O'Kane, T. J., R. J. Matear, M. A. Chamberlain, and P. R. Oke, 2014: ENSO regimes and the late 1970's climate shift: The role of synoptic weather and South Pacific Ocean spiciness. J. Comput. Phys., 271, 19-38, https://doi.org/10.1016/j.jcp. 2013.10.058.

— D. P. Monselesan, and J. S. Risbey, 2017: A multiscale reexamination of the Pacific-South American pattern. Mon. Wea. Rev., 145, 379-402, https://doi.org/10.1175/MWR-D-16-0291.1.

— climate reanalysis. Part I: System design, model configuration and data assimilation. J. Climate, 34, 5153-5169, https://doi.org/ 10.1175/JCLI-D-20-0974.1.

Oke, P. R., and Coauthors, 2013: Towards a dynamically balanced eddy-resolving ocean reanalysis: BRAN3. Ocean Modell., 67, 52-70, https://doi.org/10.1016/j.ocemod.2013.03.008.

Olsen, A., and Coauthors, 2016: The Global Ocean Data Analysis Project version 2 (GLODAPv2)-An internally consistent data product for the world ocean. Earth Syst. Sci. Data, 8, 297323, https://doi.org/10.5194/essd-8-297-2016.

Penny, S. G., D. W. Behringer, J. A. Carton, and E. Kalnay, 2015: A hybrid global ocean data assimilation system at NCEP. Mon. Wea. Rev., 143, 4660-4677, https://doi.org/10.1175/MWR-D14-00376.1.

Power, S., T. Casey, C. Folland, A. Colman, and V. Mehta, 1999: Inter-decadal modulation of the impact of ENSO on Australia. Climate Dyn., 15, 319-324, https://doi.org/10.1007/ s003820050284.

Rayner, N. A., D. E. Parker, E. B. Horton, C. K. Folland, L. V. Alexander, D. P. Rowell, E. C. Kent, and A. Kaplan, 2003: Global analyses of sea surface temperature, sea ice, and night marine air temperature since the late nineteenth century. J. Geophys. Res., 108 , 4407, https://doi.org/10.1029/2002JD002670.

Risbey, J., S. Lewandowsky, C. Langlais, D. Monselesan, T. O'Kane, and N. Oreskes, 2014: Well-estimated global surface warming in climate projections selected for ENSO phase. Nat. Climate Change, 4, 835-840, https://doi.org/10.1038/ nclimate2310.

Rodenbeck, C., R. F. Keeling, D. C. E. Bakker, N. Metzl, A. Olsen, C. Sabine, and M. Heimann, 2013: Global surface-ocean $\mathrm{pCO}_{2}$ 
and sea-air $\mathrm{CO}_{2}$ flux variability from an observation-driven ocean mixed-layer scheme. Ocean Sci., 9, 193-216, https:// doi.org/10.5194/os-9-193-2013.

Rowell, D. P., C. K. Folland, K. Maskell, and M. N. Ward, 1995: Variability of summer rainfall over tropical North Africa (1906-92): Observations and modeling. Quart. J. Roy. Meteor. Soc., 121, 669-704, https://doi.org/10.1002/qj.49712152311.

Saha, S., and Coauthors, 2010: The NCEP Climate Forecast Reanalysis System. Bull. Amer. Meteor. Soc., 91, 1015-1058, https://doi.org/10.1175/2010BAMS3001.1.

Saji, N. H., B. N. Goswami, P. N. Vinayachandran, and T. Yamagata, 1999: A dipole mode in the tropical Indian Ocean. Nature, 401, 360-363, https://doi.org/10.1038/43854.

Scaife, A. A., and Coauthors, 2018: Tropical rainfall predictions from multiple seasonal forecast systems. Int. J. Climatol., 39, 974-988, https://doi.org/10.1002/joc.5855.

Schlesinger, M. E., and N. Ramankutty, 1994: An oscillation in the global climate system of period 65-70 years. Nature, 367, 723726, https://doi.org/10.1038/367723a0.

Shu, Q., Q. Wang, Z. Song, F. Qiao, J. Zhao, M. Chu, and X. Li, 2020: Assessment of sea ice extent in CMIP6 with comparison to observations and CMIP5. Geophys. Res. Lett., 47, e2020GL087965, https://doi.org/10.1029/2020GL087965.

Sloyan, B. M., and S. R. Rintoul, 2001: The Southern Ocean limb of the global deep overturning circulation. J. Phys. Oceanogr., 31, 143-173, https://doi.org/10.1175/1520-0485(2001)031<0143: TSOLOT $>2.0 . \mathrm{CO} ; 2$.

Smeed, D., G. McCarthy, D. Rayner, B. I. Moat, W. E. Johns, M. O. Baringer, and C. S. Meinen, 2015: Atlantic meridional overturning circulation observed by the RAPID-MOCHAWBTS (RAPID-Meridional Overturning Circulation and Heatflux Array-Western Boundary Time Series) array at $26^{\circ} \mathrm{N}$ from 2004 to 2014. British Oceanographic Data Centre-Natural Environment Research Council, accessed 2020, https://doi.org/10/6qb.

Smith, D. M., and J. M. Murphy, 2007: An objective ocean temperature and salinity analysis using covariances from a global climate model. J. Geophys. Res., 112, C02022, https://doi.org/ 10.1029/2005JC003172.
Sprintall, J., S. E. Wijffels, R. Molcard, and I. Jaya, 2009: Direct estimates of the Indonesian throughflow entering the Indian Ocean: 2004-2006. J. Geophys. Res., 114, C07001, https:// doi.org/10.1029/2008JC005257.

Sutton, R. T., and D. L. R. Hodson, 2005: Atlantic Ocean forcing of North American and European summer climate. Science, 309, 115-118, https://doi.org/10.1126/science.1109496.

Swart, N. C., J. C. Fyfe, N. Gillett, and G. J. Marshall, 2015: Comparing trends in the southern annular mode and the surface westerly jet. J. Climate, 28, 8840-8859, https://doi.org/ 10.1175/JCLI-D-15-0334.1.

Talley, L. D., 2013: Closure of the global overturning circulation through the Indian, Pacific, and Southern Oceans: Schematics and transports. Oceanography, 26, 80-97, https://doi.org/10.5670/oceanog.2013.07.

Tibaldi, S., and F. Molteni, 1990: On the operational predictability of blocking. Tellus, 42A, 343-365, https://doi.org/10.3402/ tellusa.v42i3.11882.

Trenberth, K. E., and D. J. Shea, 2006: Atlantic hurricanes and natural variability in 2005. Geophys. Res. Lett., 33, L12704, https://doi.org/10.1029/2006GL026894.

Wallace, J. M., and D. S. Gutzler, 1981: Teleconnections in the geopotential height field during the Northern Hemisphere winter. Mon. Wea. Rev., 109, 784-812, https://doi.org/10.1175/ 1520-0493(1981)109<0784:TITGHF > 2.0.CO;2.

Whitworth, T., and R. Peterson, 1985: Volume transport of the Antarctic Circumpolar Current from bottom pressure measurements. J. Phys. Oceanogr., 15, 810-816, https://doi.org/ 10.1175/1520-0485(1985)015<0810:VTOTAC $>2.0$.CO;2.

Yin, Y., O. Alves, and P. R. Oke, 2011: An ensemble ocean data assimilation system for seasonal prediction. Mon. Wea. Rev., 139, 786-808, https://doi.org/10.1175/2010MWR3419.1.

Zhang, C., 2005: Madden-Julian Oscillation. Rev. Geophys., 43, RG2003, https://doi.org/10.1029/2004RG000158.

Zhang, J., and D. A. Rothrock, 2003: Modeling global sea ice with a thickness and enthalpy distribution model in generalized curvilinear coordinates. Mon. Wea. Rev., 131, 845-861, https://doi.org/10.1175/ 1520-0493(2003)131<0845:MGSIWA>2.0.CO;2.

Zweng, M. M., and Coauthors, 2019: Salinity. Vol. 2, World Ocean Atlas 2018, NOAA Atlas NESDIS 82, 50 pp. 